Research Article

\title{
Strong Convergence Theorems for Countable Families of Uniformly Quasi- $\phi$-Asymptotically Nonexpansive Mappings and a System of Generalized Mixed Equilibrium Problems
}

\author{
Siwaporn Saewan and Poom Kumam \\ Department of Mathematics, Faculty of Science, King Mongkut's University of Technology Thonburi \\ (KMUTT), Bangmod, Bangkok 10140, Thailand \\ Correspondence should be addressed to Siwaporn Saewan, si_wa_pon@hotmail.com and \\ Poom Kumam,poom.kum@kmutt.ac.th
}

Received 24 March 2011; Accepted 30 May 2011

Academic Editor: Yuming Shi

Copyright (c) 2011 S. Saewan and P. Kumam. This is an open access article distributed under the Creative Commons Attribution License, which permits unrestricted use, distribution, and reproduction in any medium, provided the original work is properly cited.

The purpose of this paper is to present a new hybrid block iterative scheme by the generalized $f$ projection method for finding a common element of the fixed point set for a countable family of uniformly quasi- $\phi$-asymptotically nonexpansive mappings and the set of solutions of the system of generalized mixed equilibrium problems in a strictly convex and uniformly smooth Banach space with the Kadec-Klee property. Furthermore, we prove that our new iterative scheme converges strongly to a common element of the aforementioned sets. The results presented in this paper improve and extend important recent results in the literature.

\section{Introduction}

Let $E$ be a Banach space with it's dual space $E^{*}$, and let $C$ be a nonempty closed convex subset of $E$. It is well known that the metric projection operator $P_{C}: E \rightarrow C$ plays an important role in nonlinear functional analysis, optimization theory, fixed point theory, nonlinear programming problems, game theory, variational inequality, complementarity problems, and so forth (see, e.g., [1, 2] and the references therein). In 1994, Alber [3] introduced and studied the generalized projections $\Pi_{E}: E \rightarrow C$ and $\pi_{C}: E^{*} \rightarrow C$ from Hilbert spaces to uniformly convex and uniformly smooth Banach spaces. Moreover, Alber [1] presented some applications of the generalized projections for approximately solving the variational inequalities and von Neumann's intersection problem in Banach spaces. In 2005, Li [2] extended the generalized projection operator from uniformly convex and uniformly smooth 
Banach spaces to reflexive Banach spaces and studied some properties of the generalized projection operator with applications to solving the variational inequality in Banach spaces. Later, Wu and Huang [4] introduced a new generalized $f$-projection operator in Banach spaces. They extended the definition of the generalized projection operators introduced by Abler [3] and proved some properties of the generalized $f$-projection operator. In 2009, Fan et al. [5] presented some basic results for the generalized $f$-projection operator and discussed the existence of solutions and approximation of the solutions for generalized variational inequalities in noncompact subsets of Banach spaces.

Block iterative method is a method which is often used by many authors to solve the convex feasibility problem (CFP) (see, [6, 7], etc.). In 2008, Plubtieng and Ungchittrakool [8] established strong convergence theorems of block iterative methods for a finite family of relatively nonexpansive mappings in a Banach space by using the hybrid method in mathematical programming. Later, Saewan and Kumam $[9,10]$ introduced a new modified block hybrid projection algorithm for finding a common element of the set of solutions of the generalized equilibrium problems and the set of common fixed points of an infinite family of closed and uniformly quasi- $\phi$-asymptotically nonexpansive mappings in a uniformly smooth and strictly convex Banach space $E$ with the Kadec-Klee property.

On the other hand, let $\left\{\theta_{i}\right\}_{i \in \Gamma}: C \times C \rightarrow \mathbb{R}$ be a bifunction, let $\left\{\varphi_{i}\right\}_{i \in \Gamma}: C \rightarrow \mathbb{R}$ be a realvalued function, and let $\left\{A_{i}\right\}_{i \in \Gamma}: C \rightarrow E^{*}$ be a monotone mapping, where $\Gamma$ is an arbitrary index set. The system of generalized mixed equilibrium problems is to find $x \in C$ such that

$$
\theta_{i}(x, y)+\left\langle A_{i} x, y-x\right\rangle+\varphi_{i}(y)-\varphi_{i}(x) \geq 0, \quad i \in \Gamma, \forall y \in C
$$

If $\Gamma$ is a singleton, then problem (1.1) reduces into the generalized mixed equilibrium problem, which is to find $x \in C$ such that

$$
\theta(x, y)+\langle A x, y-x\rangle+\varphi(y)-\varphi(x) \geq 0, \quad \forall y \in C
$$

The set of solutions (1.2) is denoted by $\operatorname{GMEP}(\theta, A, \varphi)$, that is,

$$
\operatorname{GMEP}(\theta, A, \varphi)=\{x \in C: \theta(x, y)+\langle A x, y-x\rangle+\varphi(y)-\varphi(x) \geq 0, \forall y \in C\} .
$$

If $A \equiv 0$, the problem (1.2) reduces into the mixed equilibrium problem for $\theta$, denoted by $\operatorname{MEP}(\theta, \varphi)$, which is to find $x \in C$ such that

$$
\theta(x, y)+\varphi(y)-\varphi(x) \geq 0, \quad \forall y \in C
$$

If $\theta \equiv 0$, the problem (1.2) reduces into the mixed variational inequality of Browder type, denoted by $\operatorname{VI}(C, A, \varphi)$, which is to find $x \in C$ such that

$$
\langle A x, y-x\rangle+\varphi(y)-\varphi(x) \geq 0, \quad \forall y \in C
$$

If $A \equiv 0$ and $\varphi \equiv 0$, the problem (1.2) reduces into the equilibrium problem for $\theta$, denoted by $\mathrm{EP}(\theta)$, which is to find $x \in C$ such that

$$
\theta(x, y) \geq 0, \quad \forall y \in C
$$


If $\theta \equiv 0$, the problem (1.4) reduces into the minimize problem, denoted by $\arg \min (\varphi)$, which is to find $x \in C$ such that

$$
\varphi(y)-\varphi(x) \geq 0, \quad \forall y \in C
$$

The above formulation (1.5) was shown in [11] to cover monotone inclusion problems, saddle point problems, variational inequality problems, minimization problems, optimization problems, variational inequality problems, vector equilibrium problems, and Nash equilibria in noncooperative games. In other words, the $\mathrm{EP}(\theta)$ is an unifying model for several problems arising in physics, engineering, science, optimization, economics, and so forth. Some solution methods have been proposed to solve the $\operatorname{EP}(\theta)$; see, for example, [11-24] and references therein.

A point $x \in C$ is a fixed point of a mapping $S: C \rightarrow C$ if $S x=x$, by $F(S)$ denote the set of fixed points of $S$; that is, $F(S)=\{x \in C: S x=x\}$. Recall that $S$ is said to be nonexpansive if

$$
\|S x-S y\| \leq\|x-y\|, \quad \forall x, y \in C .
$$

$S$ is said to be quasi-nonexpansive if $F(S) \neq \emptyset$ and

$$
\|x-S y\| \leq\|x-y\|, \quad \forall x \in F(S), y \in C .
$$

$S$ is said to be asymptotically nonexpansive if there exists a sequence $\left\{k_{n}\right\} \subset[1, \infty)$ with $k_{n} \rightarrow 1$ as $n \rightarrow \infty$ such that

$$
\left\|S^{n} x-S^{n} y\right\| \leq k_{n}\|x-y\|, \quad \forall x, y \in C, \forall n \geq 1 .
$$

$S$ is said to be asymptotically quasi-nonexpansive if $F(S) \neq \emptyset$ and there exists a sequence $\left\{k_{n}\right\} \subset$ $[1, \infty)$ with $k_{n} \rightarrow 1$ as $n \rightarrow \infty$ such that

$$
\left\|x-S^{n} y\right\| \leq k_{n}\|x-y\|, \quad \forall x \in F(S), y \in C, \forall n \geq 1 .
$$

Recall that a point $p$ in $C$ is said to be an asymptotic fixed point of $S$ [25] if $C$ contains a sequence $\left\{x_{n}\right\}$ which converges weakly to $p$ such that $\lim _{n \rightarrow \infty}\left\|x_{n}-S x_{n}\right\|=0$. The set of asymptotic fixed points of $S$ will be denoted by $\widetilde{F}(S)$.

Let $E$ be a real Banach space with norm $\|\cdot\|$, let $C$ be a nonempty closed convex subset of $E$, and let $E^{*}$ denote the dual of $E$. Let $\langle\cdot, \cdot\rangle$ denote the duality pairing of $E^{*}$ and $E$. If $E$ is a Hilbert space, $\langle\cdot, \cdot\rangle$ denotes an inner product on $E$. Consider the functional defined by

$$
\phi(x, y)=\|x\|^{2}-2\langle x, J y\rangle+\|y\|^{2}, \quad \text { for } x, y \in E,
$$

where $J: E \rightarrow 2^{E^{*}}$ is the normalized duality mapping.

A mapping $S$ from $C$ into itself is said to be relatively nonexpansive [26-28] if $\widetilde{F}(S)=$ $F(S) \neq \emptyset$ and

$$
\phi(p, S x) \leq \phi(p, x), \quad \forall x \in C, p \in F(S)
$$


$S$ is said to be relatively asymptotic nonexpansive [29] if $\tilde{F}(S)=F(S) \neq \emptyset$ and there exists a sequence $\left\{k_{n}\right\} \subset[1, \infty)$ with $k_{n} \rightarrow 1$ as $n \rightarrow \infty$ such that

$$
\phi\left(p, S^{n} x\right) \leq k_{n} \phi(p, x), \quad \forall x \in C, p \in F(S), n \geq 1 .
$$

The asymptotic behavior of a relatively nonexpansive mapping was studied in [30-32].

$S$ is said to be $\phi$-nonexpansive if

$$
\phi(S x, S y) \leq \phi(x, y), \quad \forall x, y \in C
$$

$S$ is said to be quasi $\phi$-nonexpansive $[17,33,34]$ if $F(S) \neq \emptyset$ and

$$
\phi(p, S x) \leq \phi(p, x), \quad \forall x \in C, p \in F(S)
$$

$S$ is said to be $\phi$-asymptotically nonexpansive if there exists a real sequence $\left\{k_{n}\right\} \subset[1, \infty)$ with $k_{n} \rightarrow 1$ as $n \rightarrow \infty$ such that

$$
\phi\left(S^{n} x, S^{n} y\right) \leq k_{n} \phi(x, y), \quad \forall x, y \in C .
$$

$S$ is said to be quasi $\phi$-asymptotically nonexpansive $[34,35]$ if $F(S) \neq \emptyset$ and there exists a real sequence $\left\{k_{n}\right\} \subset[1, \infty)$ with $k_{n} \rightarrow 1$ as $n \rightarrow \infty$ such that

$$
\phi\left(p, S^{n} x\right) \leq k_{n} \phi(p, x), \quad \forall x \in C, p \in F(S), n \geq 1 .
$$

A mapping $S$ is said to be closed if for any sequence $\left\{x_{n}\right\} \subset C$ with $x_{n} \rightarrow x$ and $S x_{n} \rightarrow y$, then $S x=y$.

Remark 1.1. It is easy to know that each relatively nonexpansive mapping is closed. The class of quasi- $\phi$-asymptotically nonexpansive mappings contains properly the class of quasi$\phi$-nonexpansive mappings as a subclass, and the class of quasi- $\phi$-nonexpansive mappings contains properly the class of relatively nonexpansive mappings as a subclass, but the converse is not true (see for more detail [30-32, 36]).

As well known if $C$ is a nonempty closed convex subset of a Hilbert space $H$ and $P_{C}: H \rightarrow C$ is the metric projection of $H$ onto $C$, then $P_{C}$ is nonexpansive. This fact actually characterizes Hilbert spaces, and consequently, it is not available in more general Banach spaces. In this connection, Alber [1] recently introduced the generalized projection $\Pi_{C}: E \rightarrow C$ is a map that assigns to an arbitrary point $x \in E$ the minimum point of the functional $\phi(x, y)$; that is, $\Pi_{C} x=\bar{x}$, where $\bar{x}$ is the solution to the minimization problem

$$
\phi(\bar{x}, x)=\inf _{y \in C} \phi(y, x) .
$$


The existence and uniqueness of the operator $\Pi_{C}$ follows from the properties of the functional $\phi(y, x)$ and the strict monotonicity of the mapping $J$ (see, e.g., [1, 37-40]). It is obvious from the definition of function $\phi$ that

$$
(\|y\|-\|x\|)^{2} \leq \phi(y, x) \leq(\|y\|-\|x\|)^{2}, \quad \forall x, y \in E .
$$

If $E$ is a Hilbert space, then $\phi(y, x)=\|y-x\|^{2}$ and $\Pi_{C}$ becomes the metric projection of $E$ onto C.

Next we recall the concept of the generalized $f$-projection operator. Let $G: C \times E^{*} \rightarrow$ $\mathbb{R} \cup\{+\infty\}$ be a functional defined as follows:

$$
G(\xi, \varpi)=\|\xi\|^{2}-2\langle\xi, \varpi\rangle+\|\varpi\|^{2}+2 \rho f(\xi),
$$

where $\xi \in C, \varpi \in E^{*}, \rho$ is positive number, and $f: C \rightarrow \mathbb{R} \cup\{+\infty\}$ is proper, convex, and lower semicontinuous. From definitions of $G$ and $f$, it is easy to see the following properties:

(1) $G(\xi, \varpi)$ is convex and continuous with respect to $\varpi$ when $\xi$ is fixed;

(2) $G(\xi, \varpi)$ is convex and lower semicontinuous with respect to $\xi$ when $\varpi$ is fixed.

Let $E$ be a real Banach space with its dual $E^{*}$. Let $C$ be a nonempty closed convex subset of $E$. We say that $\pi_{C}^{f}: E^{*} \rightarrow 2^{C}$ is generalized $f$-projection operator if

$$
\pi_{C}^{f} \varpi=\left\{u \in C: G(u, \varpi)=\inf _{\xi \in C} G(\xi, \varpi), \forall \varpi \in E^{*}\right\}
$$

In 2005, Matsushita and Takahashi [36] proposed the following hybrid iteration method (it is also called the CQ method) with generalized projection for relatively nonexpansive mapping $S$ in a Banach space E:

$$
\begin{gathered}
x_{0} \in C, \quad \text { chosen arbitrarily, } \\
y_{n}=J^{-1}\left(\alpha_{n} J x_{n}+\left(1-\alpha_{n}\right) J S x_{n}\right), \\
C_{n}=\left\{z \in C: \phi\left(z, y_{n}\right) \leq \phi\left(z, x_{n}\right)\right\}, \\
Q_{n}=\left\{z \in C:\left\langle x_{n}-z, J x_{0}-J x_{n}\right\rangle \geq 0\right\}, \\
x_{n+1}=\prod_{C_{n} \cap Q_{n}} x_{0} .
\end{gathered}
$$

They proved that $\left\{x_{n}\right\}$ converges strongly to $\Pi_{F(S)} x_{0}$, where $\Pi_{F(S)}$ is the generalized projection from $C$ onto $F(S)$.

Motivated by the results of Takahashi and Zembayashi [41], Cholamjiak and Suantai [12] proved the following strong convergence theorem by the hybrid iterative scheme for 
approximation of common fixed point of countable families of relatively quasi-nonexpansive mappings in a uniformly convex and uniformly smooth Banach space: $x_{0} \in E, x_{1}=$ $\Pi_{C_{1}} x_{0}, C_{1}=C$,

$$
\begin{gathered}
y_{n, i}=J^{-1}\left(\alpha_{n} J x_{n}+\left(1-\alpha_{n}\right) J S x_{n}\right), \\
u_{n, i}=T_{r_{m, n}}^{\theta_{m}} \mathrm{~T}_{r_{m-1, n}}^{\theta_{m-1}} \cdots T_{r_{1, n}}^{\theta_{1}} y_{n, i}, \\
C_{n+1}=\left\{z \in C_{n}: \sup _{i>1} \phi\left(z, J u_{n, i}\right) \leq \phi\left(z, J x_{n}\right)\right\}, \\
x_{n+1}=\prod_{C_{n+1}} x_{0}, \quad n \geq 1 .
\end{gathered}
$$

Then, they proved that under certain appropriate conditions imposed on $\left\{\alpha_{n}\right\}$ and $\left\{r_{n, i}\right\}$, the sequence $\left\{x_{n}\right\}$ converges strongly to $\Pi_{C_{n+1}} x_{0}$.

In 2010, $\mathrm{Li}$ et al. [42] introduced the following hybrid iterative scheme for the approximation of fixed point of relatively nonexpansive mapping using the properties of generalized $f$-projection operator in a uniformly smooth real Banach space which is also uniformly convex: $x_{0} \in C$,

$$
\begin{gathered}
y_{n}=J^{-1}\left(\alpha_{n} J x_{n}+\left(1-\alpha_{n}\right) J S x_{n}\right), \\
C_{n+1}=\left\{w \in C_{n}: G\left(w, J y_{n}\right) \leq G\left(w, J x_{n}\right)\right\}, \\
x_{n+1}=\prod_{C_{n+1}}^{f} x_{0}, \quad n \geq 0,
\end{gathered}
$$

where $\Pi_{C}^{f}: E \rightarrow 2^{C}$ is generalized $f$-projection operator. They proved the strong convergence theorem for finding an element in the fixed point set of $S$. We remark here that the results of Li et al. [42] extended and improved on the results of Matsushita and Takahashi [36].

Recently, Shehu [43] introduced a new iterative scheme by hybrid methods and proved strong convergence theorem for the approximation of a common fixed point of two countable families of weak relatively nonexpansive mappings which is also a solution to a system of generalized mixed equilibrium problems in a uniformly convex and uniformly smooth Banach space by using the properties of the generalized $f$-projection operator. Chang et al. [44] used the modified block iterative method to propose an iterative algorithm for solving the convex feasibility problems for an infinite family of quasi- $\phi$-asymptotically nonexpansive mappings. Very recently, Kim [45] and Saewan and Kumam [46] considered the shrinking projection methods for asymptotically quasi- $\phi$-nonexpansive mappings in a uniformly smooth and strictly convex Banach space which has the Kadec-Klee property.

In this paper, we introduce a new hybrid block iterative scheme of the generalized $f$ projection operator for finding a common element of the fixed point set of uniformly quasi- $\phi$ asymptotically nonexpansive mappings and the set of solutions of the system of generalized mixed equilibrium problems in a uniformly smooth and strictly convex Banach space with the Kadec-Klee property. Then, we prove that our new iterative scheme converges strongly to a common element of the aforementioned sets. The results presented in this paper improve and extend the results of Shehu [43], Chang et al. [44], Li et al. [42], Takahashi and Zembayashi [41], Cholamjiak and Suantai [12], and many authors. 


\section{Preliminaries}

A Banach space $E$ is said to be strictly convex if $\|(x+y) / 2\|<1$ for all $x, y \in E$ with $\|x\|=$ $\|y\|=1$ and $x \neq y$. Let $U=\{x \in E:\|x\|=1\}$ be the unit sphere of $E$. Then a Banach space $E$ is said to be smooth if the $\operatorname{limit}_{\lim _{t \rightarrow 0}}(\|x+t y\|-\|x\|) / t$ exists for each $x, y \in U$. It is also said to be uniformly smooth if the limit exists uniformly in $x, y \in U$. Let $E$ be a Banach space. The modulus of smoothness of $E$ is the function $\rho_{E}:[0, \infty) \rightarrow[0, \infty)$ defined by $\rho_{E}(t)=\sup \{((\|x+y\|+\|x-y\|) / 2)-1:\|x\|=1,\|y\| \leq t\}$. The modulus of convexity of $E$ is the function $\delta_{E}:[0,2] \rightarrow[0,1]$ defined by $\delta_{E}(\varepsilon)=\inf \{1-\|(x+y) / 2\|: x, y \in$ $E,\|x\|=\|y\|=1,\|x-y\| \geq \varepsilon\}$. The normalized duality mapping $J: E \rightarrow 2^{E^{*}}$ is defined by $J(x)=\left\{x^{*} \in E^{*}:\left\langle x, x^{*}\right\rangle=\|x\|^{2},\left\|x^{*}\right\|=\|x\|\right\}$. If $E$ is a Hilbert space, then $J=I$, where $I$ is the identity mapping.

Remark 2.1. If $E$ is a reflexive, strictly convex and smooth Banach space, then for $x, y \in E$, $\phi(x, y)=0$ if and only if $x=y$. It is sufficient to show that if $\phi(x, y)=0$, then $x=y$. From (1.12), we have $\|x\|=\|y\|$. This implies that $\langle x, J y\rangle=\|x\|^{2}=\|J y\|^{2}$. From the definition of $J$, one has $J x=J y$. Therefore, we have $x=y$; see $[38,40]$ for more details.

Recall that a Banach space $E$ has the Kadec-Klee property [38, 40, 47], if for any sequence $\left\{x_{n}\right\} \subset E$ and $x \in E$ with $x_{n} \rightarrow x$ and $\left\|x_{n}\right\| \rightarrow\|x\|$, then $\left\|x_{n}-x\right\| \rightarrow 0$ as $n \rightarrow \infty$. It is well known that if $E$ is a uniformly convex Banach space, then $E$ has the Kadec-Klee property.

Remark 2.2. Let $E$ be a Banach space. Then we know that

(1) if $E$ is an arbitrary Banach space, then $J$ is monotone and bounded;

(2) if $E$ is strictly convex, then $J$ is strictly monotone;

(3) if $E$ is smooth, then $J$ is single valued and semicontinuous;

(4) if $E$ is uniformly smooth, then $J$ is uniformly norm-to-norm continuous on each bounded subset of $E$;

(5) $E$ is reflexive, smooth, and strictly convex, then the normalized duality mapping $J=J_{2}$ is single valued, one-to-one, and onto;

(6) if $\mathrm{E}$ is uniformly smooth, then $E$ is smooth and reflexive;

(7) $E$ is uniformly smooth if and only if $E^{*}$ is uniformly convex;

see [38] for more details.

We also need the following lemmas for the proof of our main results.

For solving the equilibrium problem for a bifunction $\theta: C \times C \rightarrow \mathbb{R}$, let us assume that $\theta$ satisfies the following conditions.

(A1) $\theta(x, x)=0$, for all $x \in C$.

(A2) $\theta$ is monotone; that is, $\theta(x, y)+\theta(y, x) \leq 0$, for all $x, y \in C$. 
(A3) for each $x, y, z \in C$,

$$
\lim _{t \downarrow 0} \theta(t z+(1-t) x, y) \leq \theta(x, y)
$$

(A4) for each $x \in C, y \mapsto \theta(x, y)$ is convex and lower semicontinuous.

For example, let $A$ be a continuous and monotone operator of $C$ into $E^{*}$ and define

$$
\theta(x, y)=\langle A x, y-x\rangle, \quad \forall x, y \in C
$$

Then, $\theta$ satisfies (A1)-(A4). The following result is in Blum and Oettli [11].

Motivated by Combettes and Hirstoaga [13] in a Hilbert space and Takahashi and Zembayashi [48] in a Banach space, Zhang [49] obtained the following lemma.

Lemma 2.3 (Liu et al. [50], Zhang [49, Lemma 1.5]). Let $C$ be a closed convex subset of a smooth, strictly convex, and reflexive Banach space $E$. Let $\theta$ be a bifunction from $C \times C$ to $\mathbb{R}$ satisfying (A1)$(A 4)$, let $A: C \rightarrow E^{*}$ be a continuous and monotone mapping, let $\varphi: C \rightarrow \mathbb{R}$ be a semicontinuous and convex functional, for $r>0$, and let $x \in E$. Then, there exists $z \in C$ such that

$$
Q(z, y)+\frac{1}{r}\langle y-z, J z-J x\rangle \geq 0, \quad \forall y \in C,
$$

where $Q(z, y)=\theta(z, y)+\langle A z, y-z\rangle+\varphi(y)-\varphi(z)$. Furthermore, define a mapping $T_{r}: E \rightarrow C$ as follows:

$$
T_{r} x=\left\{z \in C: Q(z, y)+\frac{1}{r}\langle y-z, J z-J x\rangle \geq 0, \forall y \in C\right\}
$$

Then the following holds.

(1) $T_{r}$ is single-valued.

(2) $T_{r}$ is firmly nonexpansive; that is, for all $x, y \in E,\left\langle T_{r} x-T_{r} y, J T_{r} x-J T_{r} y\right\rangle \leq\left\langle T_{r} x-\right.$ $\left.T_{r} y, J x-J y\right\rangle$.

(3) $F\left(T_{r}\right)=\widetilde{F}\left(T_{r}\right)=\operatorname{GMEP}(\theta, A, \varphi)$.

(4) $\operatorname{GMEP}(\theta, A, \varphi)$ is closed and convex.

(5) $\phi\left(p, T_{r} z\right)+\phi\left(T_{r} z, z\right) \leq \phi(p, z)$, for all $p \in F\left(T_{r}\right)$ and $z \in E$.

For the generalized $f$-projection operator, $\mathrm{Wu}$ and Huang [4] proved the following basic properties.

Lemma 2.4 (Wu and Huang [4]). Let $E$ be a reflexive Banach space with its dual $E^{*}$ and let $C$ be a nonempty closed convex subset of E. The following statements hold.

(1) $\pi_{C}^{f} \varpi$ is nonempty closed convex subset of $C$ for all $\varpi \in E^{*}$. 
(2) If $E$ is smooth, then for all $\varpi \in E^{*}, x \in \pi_{C}^{f} \varpi$ if and only if

$$
\langle x-y, \varpi-J x\rangle+\rho f(y)-\rho f(x) \geq 0, \quad \forall y \in C .
$$

(3) If $E$ is strictly convex and $f: C \rightarrow \mathbb{R} \cup\{+\infty\}$ is positive homogeneous (i.e., $f(t x)=t f(x)$ for all $t>0$ such that $t x \in C$ where $x \in C)$, then $\pi_{C}^{f}$ is single-valued mapping.

Recently, Fan et al. [5] have shown that the condition $f$ which is positive homogeneous and appeared in [5, Lemma 2.1(iii)] can be removed.

Lemma 2.5 (Fan et al. [5]). Let $E$ be a reflexive Banach space with its dual $E^{*}$, and let $C$ be a nonempty closed convex subset of $E$. If $E$ is strictly convex, then $\pi_{C}^{f} \varpi$ is single valued.

Recall that $J$ is single value mapping when $E$ is a smooth Banach space. There exists a unique element $\varpi \in E^{*}$ such that $\varpi=J x$ where $x \in E$. This substitution for (1.21) gives

$$
G(\xi, J x)=\|\xi\|^{2}-2\langle\xi, J x\rangle+\|x\|^{2}+2 \rho f(\xi)
$$
[42]).

Now we consider the second generalized $f$-projection operator in Banach spaces (see

Definition 2.6. Let $E$ be a real smooth Banach space, and let $C$ be a nonempty closed convex subset of $E$. We say that $\Pi_{C}^{f}: E \rightarrow 2^{C}$ is generalized $f$-projection operator if

$$
\Pi_{C}^{f} x=\left\{u \in C: G(u, J x)=\inf _{\xi \in C} G(\xi, J x), \forall x \in E\right\}
$$

Lemma 2.7 (Deimling [51]). Let $E$ be a Banach space, and let $f: E \rightarrow \mathbb{R} \cup\{+\infty\}$ be a lower semicontinuous convex functional. Then there exist $x^{*} \in E^{*}$ and $\alpha \in \mathbb{R}$ such that

$$
f(x) \geq\left\langle x, x^{*}\right\rangle+\alpha, \quad \forall x \in E
$$

Lemma 2.8 (Li et al. [42]). Let E be a reflexive smooth Banach space, and C let be a nonempty closed convex subset of $E$. The following statements hold.

(1) $\Pi_{C}^{f} x$ is nonempty closed convex subset of $C$ for all $x \in E$.

(2) For all $x \in E, \widehat{x} \in \Pi_{C}^{f} x$ if and only if

$$
\langle\widehat{x}-y, J x-J \widehat{x}\rangle+\rho f(y)-\rho f(\widehat{x}) \geq 0, \quad \forall y \in C .
$$

(3) If $E$ is strictly convex, then $\Pi_{C}^{f}$ is single-valued mapping. 
Lemma 2.9 (Li et al. [42]). Let $E$ be a reflexive smooth Banach space and let $C$ be a nonempty closed convex subset of $E$, and let $x \in E, \widehat{x} \in \Pi_{C}^{f} x$. Then

$$
\phi(y, \widehat{x})+G(\widehat{x}, J x) \leq G(y, J x), \quad \forall y \in C .
$$

Remark 2.10. Let $E$ be a uniformly convex and uniformly smooth Banach space, and let $f(x)=$ 0 for all $x \in E$. Then Lemma 2.9 reduces to the property of the generalized projection operator considered by Alber [1].

Lemma 2.11 (Li et al. [42]). Let $E$ be a Banach space, and let $f: E \rightarrow \mathbb{R} \cup\{+\infty\}$ be a proper, convex, and lower semicontinuous mapping with convex domain $D(f)$. If $\left\{x_{n}\right\}$ is a sequence in $D(f)$ such that $x_{n} \rightarrow \widehat{x} \in D(f)$ and $\lim _{n \rightarrow \infty} G\left(x_{n}, J y\right)=G(\widehat{x}, J y)$, then $\lim _{n \rightarrow \infty}\left\|x_{n}\right\|=\|\widehat{x}\|$.

Lemma 2.12 (Chang et al. [44]). Let E be a real uniformly smooth and strictly convex Banach space with Kadec-Klee property, and let $C$ be a nonempty closed convex subset of $E$. Let $S: C \rightarrow C$ be a closed and quasi- $\phi$-asymptotically nonexpansive mapping with a sequence $\left\{k_{n}\right\} \subset[1, \infty), k_{n} \rightarrow 1$. Then $F(S)$ is a closed convex subset of $C$.

Lemma 2.13 (Chang et al. [44]). Let E be a uniformly convex Banach space, let $r>0$ be a positive number, and let $B_{r}(0)$ be a closed ball of $E$. Then, for any given sequence $\left\{x_{i}\right\}_{i=1}^{\infty} \subset B_{r}(0)$ and for any given sequence $\left\{\lambda_{i}\right\}_{i=1}^{\infty}$ of positive number with $\sum_{n=1}^{\infty} \lambda_{n}=1$, there exists a continuous, strictly increasing, and convex function $g:[0,2 r) \rightarrow[0, \infty)$ with $g(0)=0$ such that, for any positive integer $i$, $j$ with $i<j$,

$$
\left\|\sum_{n=1}^{\infty} \lambda_{n} x_{n}\right\|^{2} \leq \sum_{n=1}^{\infty} \lambda_{n}\left\|x_{n}\right\|^{2}-\lambda_{i} \lambda_{j} g\left(\left\|x_{i}-x_{j}\right\|\right) .
$$

Definition 2.14. (Chang et al. [44]).

(1) Let $\left\{S_{i}\right\}_{i=1}^{\infty}: C \rightarrow C$ be a sequence of mappings. $\left\{S_{i}\right\}_{i=1}^{\infty}$ is said to be a family of uniformly quasi- $\phi$-asymptotically nonexpansive mappings, if $\mathcal{F}:=\cap_{i=1}^{\infty} F\left(S_{i}\right) \neq \emptyset$, and there exists a sequence $\left\{k_{n}\right\} \subset[1, \infty)$ with $k_{n} \rightarrow 1$ such that for each $i \geq 1$

$$
\phi\left(p, S_{i}^{n} x\right) \leq k_{n} \phi(p, x), \quad \forall p \in \mathcal{F}, x \in C, \forall n \geq 1 .
$$

(2) A mapping $S: C \rightarrow C$ is said to be uniformly L-Lipschitz continuous, if there exists a constant $L>0$ such that

$$
\left\|S^{n} x-S^{n} y\right\| \leq L\|x-y\|, \quad \forall x, y \in C
$$

If $f(x) \geq 0$, it is clearly by the definition of mappings $\left\{S_{i}\right\}_{i=1}^{\infty}$ is a family of uniformly quasi- $\phi$-asymptotically nonexpansive is equivalent to if $\cap_{i=1}^{\infty} F\left(S_{i}\right) \neq \emptyset$ and there exists a sequence $\left\{k_{n}\right\} \subset[1, \infty)$ with $k_{n} \rightarrow 1$ such that for each $i \geq 1$,

$$
G\left(p, J S_{i}^{n} x\right) \leq k_{n} G(p, J x), \quad \forall p \in \mathcal{F}, x \in C, \forall n \geq 1 .
$$




\section{Strong Convergence Theorem}

Now we state and prove our main result.

Theorem 3.1. Let $C$ be a nonempty closed and convex subset of a uniformly smooth and strictly convex Banach space $E$ with the Kadec-Klee property. Let $\left\{S_{i}\right\}_{i=1}^{\infty}: C \rightarrow C$ be an infinite family of closed uniformly $L_{i}$-Lipschitz continuous and uniformly quasi- $\phi$-asymptotically nonexpansive mappings with a sequence $\left\{k_{n}\right\} \subset[1, \infty), k_{n} \rightarrow 1$, and let $f: E \rightarrow \mathbb{R}$ be a convex lower semicontinuous mapping with $C \subset \operatorname{int}(D(f))$. For each $j=1,2, \ldots, m$, let $\theta_{j}$ be a bifunction from $C \times C$ to $\mathbb{R}$ which satisfies conditions (A1)-(A4), let $A_{j}: C \rightarrow E^{*}$ be a continuous and monotone mapping, and let $\varphi_{j}: C \rightarrow \mathbb{R}$ be a lower semicontinuous and convex function. Assume that $F:=\left(\cap_{i=1}^{\infty} F\left(S_{i}\right)\right) \cap$ $\left(\cap_{j=1}^{m} \operatorname{GMEP}\left(\theta_{j}, A_{j}, \varphi_{j}\right)\right) \neq \emptyset$. For an initial point $x_{0} \in E$ with $x_{1}=\Pi_{C_{1}}^{f} x_{0}$ and $C_{1}=C$, we define the sequence $\left\{x_{n}\right\}$ as follows:

$$
\begin{gathered}
z_{n}=J^{-1}\left(\alpha_{n, 0} J x_{n}+\sum_{i=1}^{\infty} \alpha_{n, i} J S_{i}^{n} x_{n}\right), \\
y_{n}=J^{-1}\left(\beta_{n} J x_{n}+\left(1-\beta_{n}\right) J z_{n}\right), \\
u_{n}=T_{r_{m, n}}^{Q_{m}} T_{r_{m-1, n}}^{Q_{m-1}} \cdots T_{r_{2, n}}^{Q_{2}} T_{r_{1, n}}^{Q_{1}} y_{n}, \\
C_{n+1}=\left\{z \in C_{n}: G\left(z, J u_{n}\right) \leq G\left(z, J x_{n}\right)+\left(k_{n}-1\right) M_{n}\right\}, \\
x_{n+1}=\Pi_{C_{n+1}}^{f} x_{0}, \quad \forall n \geq 1,
\end{gathered}
$$

where $M_{n}=\sup _{q \in F}\left\{G\left(q, J x_{n}\right)\right\},\left\{\alpha_{n, i}\right\},\left\{\beta_{n}\right\}$ are sequences in $[0,1]$, and $\sum_{i=0}^{\infty} \alpha_{n, i}=1$, for all $n \geq 0$, satisfy the following conditions.

(i) $\left\{r_{j, n}\right\} \subset[d, \infty)$ for some $d>0$.

(ii) $\liminf _{n \rightarrow \infty} \alpha_{n, 0} \alpha_{n, i}>0$ for all $i \geq 1$, and $\liminf _{n \rightarrow \infty}\left(1-\beta_{n}\right)>0$.

(iii) $f(x) \geq 0$ for all $x \in C$. and $f(0)=0$.

Then $\left\{x_{n}\right\}$ converges strongly to $p \in F$, where $p=\Pi_{F}^{f} x_{0}$.

Proof. We split the proof into six steps.

Step 1. We first show that $C_{n+1}$ is closed and convex for each $n \geq 1$.

Clearly $C_{1}=C$ is closed and convex. Suppose that $C_{n}$ is closed and convex for each $n \in \mathbb{N}$. Since for any $z \in C_{n}$, we know that $G\left(z, J u_{n}\right) \leq G\left(z, J x_{n}\right)+\left(k_{n}-1\right) M_{n}$ is equivalent to

$$
2\left\langle z, J x_{n}-J u_{n}\right\rangle \leq\left\|x_{n}\right\|^{2}-\left\|u_{n}\right\|^{2}+\left(k_{n}-1\right) M_{n}
$$

it follow that

$$
C_{n+1}=\left\{z \in C_{n}: 2\left\langle z, J x_{n}-J u_{n}\right\rangle \leq\left\|x_{n}\right\|^{2}-\left\|u_{n}\right\|^{2}+\left(k_{n}-1\right) M_{n}\right\} .
$$

So, $C_{n+1}$ is closed and convex. This implies that $\Pi_{C_{n+1}}^{f} x_{0}$ is well defined for all $n \geq 1$. 
Step 2. We show that $F \subset C_{n}$ for all $n \geq 1$.

We show by induction that $F \subset C_{n}$ for all $n \in \mathbb{N}$. It is obvious that $F \subset C_{1}=C$. Suppose that $F \subset C_{n}$ for some $n \geq 1$. Let $q \in F \subset C_{n}$, by the convexity of $\|\cdot\|^{2}$, Lemma 2.13 , and the uniformly quasi- $\phi$-asymptotically nonexpansive of $S_{i}$, we compute

$$
\begin{aligned}
G\left(q, J z_{n}\right)= & G\left(q,\left(\alpha_{n, 0} J x_{n}+\sum_{i=1}^{\infty} \alpha_{n, i} J S_{i}^{n} x_{n}\right)\right) \\
= & \|q\|^{2}-2\left\langle q, \alpha_{n, 0} J x_{n}+\sum_{i=1}^{\infty} \alpha_{n, i} J S_{i}^{n} x_{n}\right\rangle+\left\|\alpha_{n, 0} J x_{n}+\sum_{i=1}^{\infty} \alpha_{n, i} J S_{i}^{n} x_{n}\right\|^{2}+2 \rho f(q) \\
= & \|q\|^{2}-2 \alpha_{n, 0}\left\langle q, J x_{n}\right\rangle-2 \sum_{i=1}^{\infty} \alpha_{n, i}\left\langle q, J S_{i}^{n} x_{n}\right\rangle \\
& +\left\|\alpha_{n, 0} J x_{n}+\sum_{i=1}^{\infty} \alpha_{n, i} J S_{i}^{n} x_{n}\right\|^{2}+2 \rho f(q) \\
\leq & \|q\|^{2}-2 \alpha_{n, 0}\left\langle q, J x_{n}\right\rangle-2 \sum_{i=1}^{\infty} \alpha_{n, i}\left\langle q, J S_{i}^{n} x_{n}\right\rangle+\alpha_{n, 0}\left\|J x_{n}\right\|^{2} \\
& +\sum_{i=1}^{\infty} \alpha_{n, i}\left\|J S_{i}^{n} x_{n}\right\|^{2}-\alpha_{n, 0} \alpha_{n, j} g\left\|J x_{n}-J S_{j}^{n} x_{n}\right\|+2 \rho f(q) \\
= & \|q\|^{2}-2 \alpha_{n, 0}\left\langle q, J x_{n}\right\rangle+\alpha_{n, 0}\left\|J x_{n}\right\|^{2}-2 \sum_{i=1}^{\infty} \alpha_{n, i}\left\langle q, J S_{i}^{n} x_{n}\right\rangle \\
& +\sum_{i=1}^{\infty} \alpha_{n, i}\left\|J S_{i}^{n} x_{n}\right\|^{2}-\alpha_{n, 0} \alpha_{n, j} g\left\|J x_{n}-J S_{j}^{n} x_{n}\right\|+2 \rho f(q) \\
= & \alpha_{n, 0} G\left(q, J x_{n}\right)+\sum_{i=1}^{\infty} \alpha_{n, i} G\left(q, J S_{i}^{n} x_{n}\right)-\alpha_{n, 0} \alpha_{n, j} g\left\|J x_{n}-J S_{j}^{n} x_{n}\right\| \\
\leq & \alpha_{n, 0} k_{n} G\left(q, J x_{n}\right)+\sum_{i=1}^{\infty} \alpha_{n, i} k_{n} G\left(q, J x_{n}\right)-\alpha_{n, 0} \alpha_{n, j} g\left\|J x_{n}-J S_{j}^{n} x_{n}\right\| \\
\leq & k_{n} G\left(q, J x_{n}\right) .
\end{aligned}
$$

Since $u_{n}=\Omega_{n}^{m} y_{n}$, when $\Omega_{n}^{j}=T_{r_{j, n}}^{Q_{j}} T_{r_{j-1, n}}^{Q_{j-1}} \cdots T_{r_{2, n}}^{Q_{2}} T_{r_{1, n}}^{Q_{1}}, j=1,2,3, \ldots, m, \Omega_{n}^{0}=I$, it follows from (3.4) that

$$
\begin{aligned}
G\left(q, J u_{n}\right) & =G\left(q, J \Omega_{n}^{m} y_{n}\right) \\
& \leq G\left(q, J y_{n}\right) \\
& =G\left(q, \beta_{n} J x_{n}+\left(1-\beta_{n}\right) J z_{n}\right) \\
& =\|q\|^{2}-2\left\langle q, \beta_{n} J x_{n}+\left(1-\beta_{n}\right) J z_{n}\right\rangle+\left\|\beta_{n} J x_{n}+\left(1-\beta_{n}\right) J z_{n}\right\|^{2}+2 \rho f(q)
\end{aligned}
$$


Abstract and Applied Analysis

$$
\begin{aligned}
& \leq\|q\|^{2}-2 \beta_{n}\left\langle q, J x_{n}\right\rangle-2\left(1-\beta_{n}\right)\left\langle q, J z_{n}\right\rangle+\beta_{n}\left\|x_{n}\right\|^{2}+\left(1-\beta_{n}\right)\left\|z_{n}\right\|^{2}+2 \rho f(q) \\
& =\beta_{n} G\left(q, J x_{n}\right)+\left(1-\beta_{n}\right) G\left(q, J z_{n}\right) \\
& \leq \beta_{n} G\left(q, J x_{n}\right)+\left(1-\beta_{n}\right) k_{n} G\left(q, J x_{n}\right) \\
& \leq G\left(q, J x_{n}\right)+\left(1-\beta_{n}\right)\left(k_{n}-1\right) G\left(q, J x_{n}\right) \\
& =G\left(q, J x_{n}\right)+\left(k_{n}-1\right) M_{n} .
\end{aligned}
$$

This shows that $q \in C_{n+1}$ which implies that $F \subset C_{n+1}$, and hence, $F \subset C_{n}$ for all $n \geq 1$. Since $F$ is nonempty, $C_{n}$ is a nonempty closed convex subset of $E$, and hence, $\Pi_{C_{n}}^{f}$ exist for all $n \geq 0$. This implies that the sequence $\left\{x_{n}\right\}$ is well defined.

Step 3. We show that $\left\{x_{n}\right\}$ is bounded.

Since $f: E \rightarrow \mathbb{R}$ is convex and lower semicontinuous mapping, from Lemma 2.7, we have known that there exist $x^{*} \in E^{*}$ and $\alpha \in \mathbb{R}$ such that

$$
f(x) \geq\left\langle x, x^{*}\right\rangle+\alpha, \quad \forall x \in E
$$

Since $x_{n} \in E$, it follows that

$$
\begin{aligned}
G\left(x_{n}, J x_{0}\right) & =\left\|x_{n}\right\|^{2}-2\left\langle x_{n}, J x_{0}\right\rangle+\left\|x_{0}\right\|^{2}+2 \rho f\left(x_{n}\right) \\
& \geq\left\|x_{n}\right\|^{2}-2\left\langle x_{n}, J x_{0}\right\rangle+\left\|x_{0}\right\|^{2}+2 \rho\left\langle x_{n}, x^{*}\right\rangle+2 \rho \alpha \\
& =\left\|x_{n}\right\|^{2}-2\left\langle x_{n}, J x_{0}-\rho x^{*}\right\rangle+\left\|x_{0}\right\|^{2}+2 \rho \alpha \\
& \geq\left\|x_{n}\right\|^{2}-2\left\|x_{n}\right\|\left\|J x_{0}-\rho x^{*}\right\|+\left\|x_{0}\right\|^{2}+2 \rho \alpha \\
& =\left(\left\|x_{n}\right\|-\left\|J x_{0}-\rho x^{*}\right\|\right)^{2}+\left\|x_{0}\right\|^{2}-\left\|J x_{0}-\rho x^{*}\right\|^{2}+2 \rho \alpha .
\end{aligned}
$$

For each $q \in F \subset C_{n}$ and by the definition of $C_{n}$ that $x_{n}=\Pi_{C_{n}}^{f} x_{0}$, it follows from (3.7) that

$$
G\left(q, J x_{0}\right) \geq G\left(x_{n}, J x_{0}\right) \geq\left(\left\|x_{n}\right\|-\left\|J x_{0}-\rho x^{*}\right\|\right)^{2}+\left\|x_{0}\right\|^{2}-\left\|J x_{0}-\rho x^{*}\right\|^{2}+2 \rho \alpha .
$$

This implies that $\left\{x_{n}\right\}$ is bounded and so are $\left\{G\left(x_{n}, J x_{0}\right)\right\}$.

Step 4. We show that $\lim _{n \rightarrow \infty}\left\|u_{n}-x_{n}\right\|=0$ and $\lim _{n \rightarrow \infty}\left\|J u_{n}-J x_{n}\right\|=0$. we get

By the fact that $x_{n+1}=\Pi_{C_{n+1}}^{f} x_{0} \in C_{n+1} \subset C_{n}$ and $x_{n}=\Pi_{C_{n}}^{f} x_{0}$, followed by Lemma 2.9,

$$
0 \leq\left(\left\|x_{n+1}\right\|-\left\|x_{n}\right\|\right)^{2} \leq \phi\left(x_{n+1}, x_{n}\right) \leq G\left(x_{n+1}, J x_{0}\right)-G\left(x_{n}, J x_{0}\right) .
$$


This implies that $\left\{G\left(x_{n}, J x_{0}\right)\right\}$ is nondecreasing. So, we obtain that $\lim _{n \rightarrow \infty} G\left(x_{n}, J x_{0}\right)$ exist, and taking $n \rightarrow \infty$, we obtain that

$$
\lim _{n \rightarrow \infty} \phi\left(x_{n+1}, x_{n}\right)=0
$$

Since $\left\{x_{n}\right\}$ is bounded in $C$ and $E$ is reflexive, we can assume that $x_{n} \rightarrow p$. From the fact that $x_{n}=\Pi_{C_{n}}^{f} x_{0}$ when $C_{n}$ is closed and convex for each $n \geq 1$, it is easy to see that $p \in C_{n}$ and we get

$$
G\left(x_{n}, J x_{0}\right) \leq G\left(p, J x_{0}\right), \quad \forall n \geq 1
$$

Since $f$ is convex and lower semicontinuous, we have

$$
\begin{aligned}
\liminf _{n \rightarrow \infty} G\left(x_{n}, J x_{0}\right) & =\liminf _{n \rightarrow \infty}\left\{\left\|x_{n}\right\|^{2}-2\left\langle x_{n}, J x_{0}\right\rangle+\left\|x_{0}\right\|^{2}+2 \rho f\left(x_{n}\right)\right\} \\
& \geq\|p\|^{2}-2\left\langle p, J x_{0}\right\rangle+\left\|x_{0}\right\|^{2}+2 \rho f(p) \\
& =G\left(p, J x_{0}\right) .
\end{aligned}
$$

By (3.11) and (3.12), we get

$$
G\left(p, J x_{0}\right) \leq \liminf _{n \rightarrow \infty} G\left(x_{n}, J x_{0}\right) \leq \limsup _{n \rightarrow \infty} G\left(x_{n}, J x_{0}\right) \leq G\left(p, J x_{0}\right) .
$$

That is $\lim _{n \rightarrow \infty} G\left(x_{n}, J x_{0}\right)=G\left(p, J x_{0}\right)$, by Lemma 2.11, we have $\left\|x_{n}\right\| \rightarrow\|p\|$, from the KadecKlee property of $E$, we obtain that

$$
\lim _{n \rightarrow \infty} x_{n}=p
$$

and we also have

$$
\lim _{n \rightarrow \infty} x_{n+1}=p
$$

Since $x_{n+1}=\Pi_{C_{n+1}}^{f} x_{0} \in C_{n+1} \subset C_{n}$ and from the definition of $C_{n+1}$, we have

$$
G\left(x_{n+1}, J u_{n}\right) \leq G\left(x_{n+1}, J x_{n}\right)+\left(k_{n}-1\right) M_{n}, \quad \forall n \in \mathbb{N},
$$

is equivalent to

$$
\phi\left(x_{n+1}, u_{n}\right) \leq \phi\left(x_{n+1}, x_{n}\right)+\left(k_{n}-1\right) M_{n}, \quad \forall n \in \mathbb{N} .
$$

By (3.10) and in view of $\lim _{n \rightarrow \infty}\left(k_{n}-1\right) M_{n}=0$, we also have

$$
\lim _{n \rightarrow \infty} \phi\left(x_{n+1}, u_{n}\right)=0
$$


From (1.20), it follow that

$$
\left(\left\|x_{n+1}\right\|-\left\|u_{n}\right\|\right)^{2} \longrightarrow 0
$$

Since $\left\|x_{n+1}\right\| \rightarrow\|p\|$, we also have

$$
\left\|u_{n}\right\| \longrightarrow\|p\| \text { as } n \longrightarrow \infty
$$

It follows that

$$
\left\|J u_{n}\right\| \longrightarrow\|J p\| \text { as } n \longrightarrow \infty
$$

This implies that $\left\{\left\|J u_{n}\right\|\right\}$ is bounded in $E^{*}$. Note that $E$ is reflexive and $E^{*}$ is also reflexive; we can assume that $J u_{n} \rightarrow x^{*} \in E^{*}$. In view of the reflexive of $E$, we see that $J(E)=E^{*}$. Hence, there exists $x \in E$ such that $J x=x^{*}$. It follows that

$$
\begin{aligned}
\phi\left(x_{n+1}, u_{n}\right) & =\left\|x_{n+1}\right\|^{2}-2\left\langle x_{n+1}, J u_{n}\right\rangle+\left\|u_{n}\right\|^{2} \\
& =\left\|x_{n+1}\right\|^{2}-2\left\langle x_{n+1}, J u_{n}\right\rangle+\left\|J u_{n}\right\|^{2} .
\end{aligned}
$$

Taking $\liminf _{n \rightarrow \infty}$ on both sides of the equality above and in view of the weak lower semicontinuity of norm $\|\cdot\|$, it yields that

$$
\begin{aligned}
0 & \geq\|p\|^{2}-2\left\langle p, x^{*}\right\rangle+\left\|x^{*}\right\|^{2} \\
& =\|p\|^{2}-2\langle p, J x\rangle+\|J x\|^{2} \\
& =\|p\|^{2}-2\langle p, J x\rangle+\|x\|^{2} \\
& =\phi(p, x) .
\end{aligned}
$$

That is $p=x$, which implies that $x^{*}=J p$. It follows that $J u_{n} \rightarrow J p \in E^{*}$. From (3.21) and the Kadec-Klee property of $E^{*}$; that, is $J u_{n} \rightarrow J p$ as $n \rightarrow \infty$, we known that $J^{-1}: E^{*} \rightarrow E$ is norm-weak*-continuous, that is, $u_{n} \rightarrow p$. From (3.20) and the Kadec-Klee property of $E$, we have

$$
\lim _{n \rightarrow \infty} u_{n}=p
$$

Since $\left\|x_{n}-u_{n}\right\| \leq\left\|x_{n}-p\right\|+\left\|p-u_{n}\right\|$, it follows that

$$
\lim _{n \rightarrow \infty}\left\|x_{n}-u_{n}\right\|=0
$$

From $J$ that is uniformly norm-to-norm continuous on bounded subsets of $E$, we obtain

$$
\lim _{n \rightarrow \infty}\left\|J u_{n}-J x_{n}\right\|=0
$$


Step 5. We will show that $p \in F:=\left(\cap_{i=1}^{\infty} F\left(S_{i}\right)\right) \cap\left(\cap_{j=1}^{m} \operatorname{GMEP}\left(\theta_{j}, A_{j}, \varphi_{j}\right)\right)$.

(a) We show that $p \in \cap_{i=1}^{\infty} F\left(S_{i}\right)$.

For $q \in F$, we note that

$$
\begin{aligned}
\phi\left(q, x_{n}\right)-\phi\left(q, u_{n}\right)+\left(k_{n}-1\right) M_{n}= & \left\|x_{n}\right\|^{2}-\left\|u_{n}\right\|^{2}-2\left\langle q, J x_{n}-J u_{n}\right\rangle+\left(k_{n}-1\right) M_{n} \\
\leq & \left\|x_{n}-u_{n}\right\|\left(\left\|x_{n}\right\|+\left\|u_{n}\right\|\right)+2\|q\|\left\|J x_{n}-J u_{n}\right\| \\
& +\left(k_{n}-1\right) M_{n} .
\end{aligned}
$$

It follows from $\left\|x_{n}-u_{n}\right\| \rightarrow 0,\left\|J x_{n}-J u_{n}\right\| \rightarrow 0$ and $\left(k_{n}-1\right) M_{n} \rightarrow 0$ as $n \rightarrow \infty$ that

$$
\phi\left(q, x_{n}\right)-\phi\left(q, u_{n}\right)+\left(k_{n}-1\right) M_{n} \longrightarrow 0 \quad \text { as } n \longrightarrow \infty
$$

For any $i \geq 1$ and any $q \in F$, it follows from (3.4) and (3.5) that

$$
\begin{aligned}
G\left(q, J u_{n}\right) \leq & \beta_{n} G\left(q, J x_{n}\right)+\left(1-\beta_{n}\right) G\left(q, J z_{n}\right) \\
\leq & \beta_{n} G\left(q, J x_{n}\right)+\left(1-\beta_{n}\right)\left(\alpha_{n, 0} k_{n} G\left(q, J x_{n}\right)\right. \\
& \left.\quad+\sum_{i=1}^{\infty} \alpha_{n, i} k_{n} G\left(q, J x_{n}\right)-\alpha_{n, 0} \alpha_{n, j} g\left\|J x_{n}-J S_{j}^{n} x_{n}\right\|\right) \\
= & \beta_{n} G\left(q, J x_{n}\right)+\left(1-\beta_{n}\right)\left(k_{n} G\left(q, J x_{n}\right)-\alpha_{n, 0} \alpha_{n, j} g\left\|J x_{n}-J S_{j}^{n} x_{n}\right\|\right) \\
= & \beta_{n} G\left(q, J x_{n}\right)+\left(1-\beta_{n}\right) k_{n} G\left(q, J x_{n}\right)-\left(1-\beta_{n}\right) \alpha_{n, 0} \alpha_{n, j} g\left\|J x_{n}-J S_{j}^{n} x_{n}\right\| \\
\leq & G\left(q, J x_{n}\right)+\left(k_{n}-1\right) M_{n}-\left(1-\beta_{n}\right) \alpha_{n, 0} \alpha_{n, j} g\left\|J x_{n}-J S_{j}^{n} x_{n}\right\| .
\end{aligned}
$$

It follows that

$$
\alpha_{n, 0} \alpha_{n, j} g\left\|J x_{n}-J S_{j}^{n} x_{n}\right\| \leq \frac{1}{\left(1-\beta_{n}\right)}\left(G\left(q, J x_{n}\right)-G\left(q, J u_{n}\right)+\left(k_{n}-1\right) M_{n}\right),
$$

is in equivalence to

$$
\alpha_{n, 0} \alpha_{n, j} g\left\|J x_{n}-J S_{j}^{n} x_{n}\right\| \leq \frac{1}{\left(1-\beta_{n}\right)}\left(\phi\left(q, x_{n}\right)-\phi\left(q, u_{n}\right)+\left(k_{n}-1\right) M_{n}\right) .
$$

From (3.28), $\liminf _{n \rightarrow \infty} \alpha_{n, 0} \alpha_{n, i}>0$ and $\liminf _{n \rightarrow \infty}\left(1-\beta_{n}\right)>0$, we see that

$$
g\left(\left\|J x_{n}-J S_{j}^{n} x_{n}\right\|\right) \longrightarrow 0, \quad n \longrightarrow \infty
$$


It follows from the property of $g$ that

$$
\lim _{n \rightarrow \infty}\left\|J x_{n}-J S_{j}^{n} x_{n}\right\|=0, \quad \forall j \geq 1
$$

Since $x_{n} \rightarrow p$ and $J$ is uniformly continuous, it yields that $J x_{n} \rightarrow J p$. Thus from (3.33), we have

$$
J S_{i}^{n} x_{n} \longrightarrow J p, \quad \forall i \geq 1
$$

Since $J^{-1}: E^{*} \rightarrow E$ is norm-weak ${ }^{*}$-continuous, we also have

$$
S_{i}^{n} x_{n} \rightarrow p, \quad \forall i \geq 1
$$

On the other hand, for each $i \geq 1$, we observe that

$$
\left|\left\|S_{i}^{n} x_{n}\right\|-\|p\|\right|=\left|\left\|J\left(S_{i}^{n} x_{n}\right)\right\|-\|J p\|\right| \leq\left\|J\left(S_{i}^{n} x_{n}\right)-J p\right\| .
$$

In view of (3.34), we obtain $\left\|S_{i}^{n} x_{n}\right\| \rightarrow\|p\|$ for each $i \geq 1$. Since $E$ has the Kadec-Klee property, we get

$$
S_{i}^{n} x_{n} \longrightarrow p \quad \text { for each } i \geq 1, n \in \mathbb{N}
$$

By the assumption that for each $i \geq 1, S_{i}$ is uniformly $L_{i}$-Lipschitz continuous, so we have

$$
\begin{aligned}
\left\|S_{i}^{n+1} x_{n}-S_{i}^{n} x_{n}\right\| & \leq\left\|S_{i}^{n+1} x_{n}-S_{i}^{n+1} x_{n+1}\right\|+\left\|S_{i}^{n+1} x_{n+1}-x_{n+1}\right\|+\left\|x_{n+1}-x_{n}\right\|+\left\|x_{n}-S_{i}^{n} x_{n}\right\| \\
& \leq\left(L_{i}+1\right)\left\|x_{n+1}-x_{n}\right\|+\left\|S_{i}^{n+1} x_{n+1}-x_{n+1}\right\|+\left\|x_{n}-S_{i}^{n} x_{n}\right\| .
\end{aligned}
$$

By (3.14), (3.15), and (3.37), it yields that $\left\|S_{i}^{n+1} x_{n}-S_{i}^{n} x_{n}\right\| \rightarrow 0, n \rightarrow \infty$, for all $i \geq 1$. From $S_{i}^{n} x_{n} \rightarrow p$, we get $S_{i}^{n+1} x_{n} \rightarrow p$, that is, $S_{i} S_{i}^{n} x_{n} \rightarrow p$. In view of the closeness of $S_{i}$, we have $S_{i} p=p$, for all $i \geq 1$. This imply that $p \in \cap_{i=1}^{\infty} F\left(S_{i}\right)$.

(b) We show that $p \in \cap_{j=1}^{m} \operatorname{GMEP}\left(\theta_{j}, A_{j}, \varphi_{j}\right)$.

Since $x_{n+1}=\Pi_{C_{n+1}}^{f} x_{0} \in C_{n+1} \subset C_{n}$ and from (3.5), we have

$$
G\left(x_{n+1}, J y_{n}\right) \leq G\left(x_{n+1}, J x_{n}\right)+\left(k_{n}-1\right) M_{n}
$$

is in equivalence to

$$
\phi\left(\mathrm{x}_{n+1}, y_{n}\right) \leq \phi\left(x_{n+1}, x_{n}\right)+\left(k_{n}-1\right) M_{n}
$$


From (3.10) and $\left(k_{n}-1\right) M_{n} \rightarrow 0$, as $n \rightarrow \infty$, we see that

$$
\lim _{n \rightarrow \infty} \phi\left(x_{n+1}, y_{n}\right)=0
$$

From (1.20), it follows that

$$
\left(\left\|x_{n+1}\right\|-\left\|y_{n}\right\|\right)^{2} \longrightarrow 0
$$

Since $\left\|x_{n+1}\right\| \rightarrow\|p\|$, we have

$$
\left\|y_{n}\right\| \longrightarrow\|p\|, \quad \text { as } n \longrightarrow \infty
$$

It follow that

$$
\left\|J y_{n}\right\| \longrightarrow\|J p\| \quad \text { as } n \longrightarrow \infty \text {. }
$$

This implies that $\left\{\left\|J y_{n}\right\|\right\}$ is bounded in $E^{*}$ and $E^{*}$ is reflexive; we can assume that $J y_{n} \rightarrow$ $y^{*} \in E^{*}$. In view of $J(E)=E^{*}$. Hence, there exists $y \in E$ such that $J y=y^{*}$. It follows that

$$
\begin{aligned}
\phi\left(x_{n+1}, y_{n}\right) & =\left\|x_{n+1}\right\|^{2}-2\left\langle x_{n+1}, J y_{n}\right\rangle+\left\|y_{n}\right\|^{2} \\
& =\left\|x_{n+1}\right\|^{2}-2\left\langle x_{n+1}, J y_{n}\right\rangle+\left\|J y_{n}\right\|^{2} .
\end{aligned}
$$

Taking $\liminf \operatorname{in}_{n \rightarrow \infty}$ on both sides of the equality above and in view of the weak lower semicontinuous of norm $\|\cdot\|$, it yields that

$$
\begin{aligned}
0 & \geq\|p\|^{2}-2\left\langle p, y^{*}\right\rangle+\left\|y^{*}\right\|^{2} \\
& =\|p\|^{2}-2\langle p, J y\rangle+\|J y\|^{2} \\
& =\|p\|^{2}-2\langle p, J y\rangle+\|y\|^{2} \\
& =\phi(p, y) .
\end{aligned}
$$

That is $p=y$, which implies that $y^{*}=J p$. It follows that $J y_{n} \rightarrow J p \in E^{*}$. From (3.44) and the Kadec-Klee property of $E^{*}$, that is, $J u_{n} \rightarrow J p$ as $n \rightarrow \infty$, note that $J^{-1}: E^{*} \rightarrow E$ is norm-weak*-continuous, that is, $y_{n} \rightarrow p$. From (3.43) and the Kadec-Klee property of $E$, we have

$$
\lim _{n \rightarrow \infty} y_{n}=p
$$


For $q \in F \subset C_{n}$, by nonexpansiveness, we observe that

$$
\begin{aligned}
\phi\left(q, u_{n}\right) & =\phi\left(q, \Omega_{n}^{m} y_{n}\right) \\
& \leq \phi\left(q, \Omega_{n}^{m-1} y_{n}\right) \\
& \leq \phi\left(q, \Omega_{n}^{m-2} y_{n}\right) \\
& \vdots \\
& \leq \phi\left(q, \Omega_{n}^{j} y_{n}\right) .
\end{aligned}
$$

By Lemma (2.12)(5), we have for $j=1,2,3, \ldots, m$

$$
\begin{aligned}
\phi\left(\Omega_{n}^{j} y_{n}, y_{n}\right) & \leq \phi\left(q, y_{n}\right)-\phi\left(q, \Omega_{n}^{j} y_{n}\right) \\
& \leq \phi\left(q, x_{n}\right)-\phi\left(q, \Omega_{n}^{j} y_{n}\right)+\left(k_{n}-1\right) M_{n} \\
& \leq \phi\left(q, x_{n}\right)-\phi\left(q, u_{n}\right)+\left(k_{n}-1\right) M_{n} .
\end{aligned}
$$

From (3.28), we get $\phi\left(\Omega_{n}^{j} y_{n}, y_{n}\right) \rightarrow 0$ as $n \rightarrow \infty$, for $j=1,2,3, \ldots, m$. From (1.20), it follow that

$$
\left(\left\|\Omega_{n}^{j} y_{n}\right\|-\left\|y_{n}\right\|\right)^{2} \longrightarrow 0
$$

Since $\left\|y_{n}\right\| \rightarrow\|p\|$, we also have

$$
\left\|\Omega_{n}^{j} y_{n}\right\| \longrightarrow\|p\| \quad \text { as } n \longrightarrow \infty
$$

Since $\left\{\Omega_{n}^{j} y_{n}\right\}$ is bounded and $E$ is reflexive, without loss of generality, we may assume that $\Omega_{n}^{j} y_{n} \rightarrow h$. From the first step, we have known that $C_{n}$ is closed and convex for each $n \geq 1$, it is obvious that $h \in C_{n}$. Again since

$$
\phi\left(\Omega_{n}^{j} y_{n}, y_{n}\right)=\left\|\Omega_{n}^{j} y_{n}\right\|^{2}-2\left\langle\Omega_{n}^{j} y_{n}, J y_{n}\right\rangle+\left\|y_{n}\right\|^{2},
$$

taking $\lim \inf _{n \rightarrow \infty}$ on both sides of the equality above, we have

$$
\begin{aligned}
0 & \geq\|h\|^{2}-2\langle h, J p\rangle+\|p\|^{2} \\
& =\phi(h, p) .
\end{aligned}
$$


This implies that $h=p$, for all $j=1,2,3, \ldots m$, then it follow that

$$
\Omega_{n}^{j} y_{n} \rightarrow p,
$$

from (3.51), (3.54) and the Kadec-Klee property, we have

$$
\lim _{n \rightarrow \infty} \Omega_{n}^{j} y_{n}=p \quad \forall j=1,2,3, \ldots, m
$$

By using the triangle inequality, we obtain

$$
\left\|\Omega_{n}^{j} y_{n}-\Omega_{n}^{j-1} y_{n}\right\| \leq\left\|\Omega_{n}^{j} y_{n}-p\right\|+\left\|p-\Omega_{n}^{j-1} y_{n}\right\| .
$$

Hence, we obtain that

$$
\lim _{n \rightarrow \infty}\left\|\Omega_{n}^{j} y_{n}-\Omega_{n}^{j-1} y_{n}\right\|=0, \quad \forall j=1,2,3, \ldots, m
$$

Since $\left\{r_{j, n}\right\} \subset[d, \infty)$ and $J$ is uniformly norm-to-norm continuous on bounded subsets, so

$$
\lim _{n \rightarrow \infty} \frac{\left\|J \Omega_{n}^{j} y_{n}-J \Omega_{n}^{j-1} y_{n}\right\|}{r_{j, n}}=0, \quad \forall j=1,2,3, \ldots, m
$$

From Lemma 2.3, we get for $j=1,2,3, \ldots, m$

$$
Q_{j}\left(\Omega_{n}^{j} y_{n}, y\right)+\frac{1}{r_{j, n}}\left\langle y-\Omega_{n}^{j} y_{n}, J \Omega_{n}^{j} y_{n}-J \Omega_{n}^{j-1} y_{n}\right\rangle \geq 0, \quad \forall y \in C
$$

From (A2), we get

$$
\frac{1}{r_{j, n}}\left\langle y-\Omega_{n}^{j} y_{n}, J \Omega_{n}^{j} y_{n}-J \Omega_{n}^{j-1} y_{n}\right\rangle \geq Q_{j}\left(y, \Omega_{n}^{j} y_{n}\right), \quad \forall y \in C, \forall j=1,2,3, \ldots, m .
$$

From (3.55) and (3.58), we have

$$
0 \geq Q_{j}(y, p), \quad \forall y \in C, \forall j=1,2,3, \ldots, m
$$

For $t$ with $0<t \leq 1$ and $y \in C$, let $y_{t}=t y+(1-t) p$. Then, we get that $y_{t} \in C$. From (3.61), it follows that

$$
Q_{j}\left(y_{t}, p\right) \leq 0, \quad \forall y \in C, \forall j=1,2,3, \ldots, m
$$


By the conditions (A1) and (A4), we have for $j=1,2,3, \ldots, m$

$$
\begin{aligned}
0 & =Q_{j}\left(y_{t}, y_{t}\right) \\
& \leq t Q_{j}\left(y_{t}, y\right)+(1-t) Q_{j}\left(y_{t}, p\right) \\
& \leq t Q_{j}\left(y_{t}, y\right) \\
& \leq Q_{j}\left(y_{t}, y\right)
\end{aligned}
$$

From (A3), we get

$$
\begin{aligned}
0 & \leq Q_{j}\left(y_{t}, y\right) \\
& =Q_{j}(t y+(1-t) p, y),
\end{aligned}
$$

and letting $t \rightarrow 0$, we have

$$
0=\lim _{n \rightarrow \infty} 0 \leq \lim _{n \rightarrow \infty} Q_{j}(t y+(1-t) p, y) \leq Q_{j}(p, y), \quad \forall y \in C, \forall j=1,2,3, \ldots m
$$

This implies that $p \in \operatorname{GMEP}\left(\theta_{j}, A_{j}, \varphi_{j}\right)$, for all $j=1,2,3, \ldots m$. Therefore, $p \in$ $\cap_{j=1}^{m} \operatorname{GMEP}\left(\theta_{j}, A_{j}, \varphi_{j}\right)$. Hence, from (a) and (b), we obtain $p \in F$.

Step 6. We show that $p=\Pi_{F}^{f} x_{0}$.

Since $F$ is closed and convex set from Lemma 2.8, we have $\Pi_{F}^{f} x_{0}$ is single value, denote by $v$. From $x_{n}=\Pi_{C_{n}}^{f} x_{0}$ and $v \in F \subset C_{n}$, we also have

$$
G\left(x_{n}, J x_{0}\right) \leq G\left(v, J x_{0}\right), \quad \forall n \geq 1 .
$$

By definition of $G$ and $f$, we know that, for each given $x, G(\xi, J x)$ is convex and lower semicontinuous with respect to $\xi$. So

$$
G\left(p, J x_{0}\right) \leq \liminf _{n \rightarrow \infty} G\left(x_{n}, J x_{0}\right) \leq \limsup _{n \rightarrow \infty} G\left(x_{n}, J x_{0}\right) \leq G\left(v, J x_{0}\right)
$$

From definition of $\Pi_{F}^{f} x_{0}$ and $p \in F$, we can conclude that $v=p=\Pi_{F}^{f} x_{0}$ and $x_{n} \rightarrow p$ as $n \rightarrow \infty$. This completes the proof.

For a special case that $i=1,2$, we can obtain the following results on a pair of quasi- $\phi$ asymptotically nonexpansive mappings immediately from Theorem 3.1.

Corollary 3.2. Let $C$ be a nonempty closed and convex subset of a uniformly smooth and strictly convex Banach space $E$ with the Kadec-Klee property, and let $f: E \rightarrow \mathbb{R}$ be a convex lower semicontinuous mapping with $C \subset \operatorname{int}(D(f))$. Let $S_{1}, S_{2}: C \rightarrow C$ be closed uniformly $L_{1}, L_{2}$-Lipschitz continuous and quasi- $\phi$-asymptotically nonexpansive mappings with a sequence $\left\{k_{n}^{1}\right\} \subset[1, \infty), k_{n}^{1} \rightarrow 1$ and 
$\left\{k_{n}^{2}\right\} \subset[1, \infty), k_{n}^{2} \rightarrow 1$, respectively, and let $\left\{k_{n}\right\}=\sup \left\{\left\{k_{n}^{1}\right\},\left\{k_{n}^{2}\right\}\right\}$. For each $j=1,2, \ldots, m$, let $\theta_{j}$ be a bifunction from $C \times C$ to $\mathbb{R}$ which satisfies conditions (A1)-(A4), let $A_{j}: C \rightarrow E^{*}$ be a continuous and monotone mapping and let $\varphi_{j}: C \rightarrow \mathbb{R}$ be a lower semicontinuous and convex function. Assume that $F:=\left(F\left(S_{1}\right) \cap F\left(S_{2}\right)\right) \cap\left(\cap_{j=1}^{m} \operatorname{GMEP}\left(\theta_{j}, A_{j}, \varphi_{j}\right)\right) \neq \emptyset$. For an initial point $x_{0} \in E$ with $x_{1}=\Pi_{C_{1}}^{f} x_{0}$ and $C_{1}=C$, we define the sequence $\left\{x_{n}\right\}$ as follows:

$$
\begin{gathered}
z_{n}=J^{-1}\left(\alpha_{n, 0} J x_{n}+\alpha_{n, 1} J S_{1}^{n} x_{n}+\alpha_{n, 2} J S_{2}^{n} x_{n}\right), \\
y_{n}=J^{-1}\left(\beta_{n} J x_{n}+\left(1-\beta_{n}\right) J z_{n}\right), \\
u_{n}=T_{r_{m, n}}^{Q_{m}} T_{r_{m-1, n}}^{Q_{m-1}} \cdots T_{r_{2, n}}^{Q_{2}} T_{r_{1, n}}^{Q_{1}} y_{n}, \\
C_{n+1}=\left\{z \in C_{n}: G\left(z, J u_{n}\right) \leq G\left(z, J x_{n}\right)+\left(k_{n}-1\right) M_{n}\right\}, \\
x_{n+1}=\Pi_{C_{n+1}}^{f} x_{0}, \quad \forall n \geq 1,
\end{gathered}
$$

where $M_{n}=\sup _{q \in F}\left\{G\left(q, J x_{n}\right)\right\},\left\{\alpha_{n, i}\right\}_{i=0}^{2}$ and $\left\{\beta_{n}\right\}$ are sequences in $[0,1]$ such that $\sum_{i=0}^{2} \alpha_{n, i}=1$ for all $n \geq 0$ and satisfy the following conditions.

(i) $\left\{r_{j, n}\right\} \subset[d, \infty)$ for some $d>0$.

(ii) $\lim \inf _{n \rightarrow \infty} \alpha_{n, 0} \alpha_{n, i}>0$ for all $i=1,2$, and $\liminf _{n \rightarrow \infty}\left(1-\beta_{n}\right)>0$.

(iii) $f(x) \geq 0$ for all $x \in C$, and $f(0)=0$.

Then $\left\{x_{n}\right\}$ converges strongly to $p \in F$, where $p=\Pi_{F}^{f} x_{0}$.

Remark 3.3. Corollary 3.2 improves and extends the result of Shehu [43, Theorem 3.1] following senses:

(i) for the mappings, we extend the mappings from two closed weak relatively nonexpansive mappings (or relatively quasi-nonexpansive) mappings to a countable infinite family of closed and uniformly quasi- $\phi$-asymptotically nonexpansive mappings;

(ii) for the framework of spaces, we extend the space from a uniformly smooth and uniformly convex Banach space to a uniformly smooth and strictly convex Banach space with the Kadec-Klee property.

If $S_{i}=S$ for each $i \in \mathbb{N}$, then Theorem 3.1 is reduced to the following corollary.

Corollary 3.4. Let $C$ be a nonempty closed and convex subset of a uniformly smooth and strictly convex Banach space $E$ with the Kadec-Klee property. Let $S: C \rightarrow C$ be an infinite family of closed uniformly L-Lipschitz continuous and quasi- $\phi$-asymptotically nonexpansive mappings with a sequence $\left\{k_{n}\right\} \subset[1, \infty), k_{n} \rightarrow 1$, and let $f: E \rightarrow \mathbb{R}$ be a convex lower semicontinuous mapping with $C \subset \operatorname{int}(D(f))$. For each $j=1,2, \ldots, m$, let $\theta_{j}$ be a bifunction from $C \times C$ to $\mathbb{R}$ which satisfies conditions (A1)-(A4), let $A_{j}: C \rightarrow E^{*}$ be a continuous and monotone mapping, and let $\varphi_{j}: C \rightarrow \mathbb{R}$ be a lower semicontinuous and convex function. Assume that $F:=F(S) \cap$ $\left(\cap_{j=1}^{m} \operatorname{GMEP}\left(\theta_{j}, A_{j}, \varphi_{j}\right)\right) \neq \emptyset$. For an initial point $x_{0} \in E$ with $x_{1}=\Pi_{C_{1}}^{f} x_{0}$ and $C_{1}=C$, we define the 
sequence $\left\{x_{n}\right\}$ as follows:

$$
\begin{gathered}
z_{n}=J^{-1}\left(\alpha_{n} J x_{n}+\left(1-\alpha_{n}\right) J S^{n} x_{n}\right), \\
y_{n}=J^{-1}\left(\beta_{n} J x_{n}+\left(1-\beta_{n}\right) J z_{n}\right), \\
u_{n}=T_{r_{m, n}}^{Q_{m}} T_{r_{m-1, n}}^{Q_{m-1}} \cdots T_{r_{2, n}}^{Q_{2}} T_{r_{1, n}}^{Q_{1}} y_{n}, \\
C_{n+1}=\left\{z \in C_{n}: G\left(z, J u_{n}\right) \leq G\left(z, J x_{n}\right)+\left(k_{n}-1\right) M_{n}\right\}, \\
x_{n+1}=\Pi_{C_{n+1}}^{f} x_{0}, \quad \forall n \geq 1,
\end{gathered}
$$

where $M_{n}=\sup _{q \in F}\left\{G\left(q, J x_{n}\right)\right\},\left\{\alpha_{n}\right\}$ and $\left\{\beta_{n}\right\}$ are sequences in $[0,1]$ and satisfy the following conditions:

(i) $\left\{r_{j, n}\right\} \subset[d, \infty)$ for some $d>0$.

(ii) $\liminf _{n \rightarrow \infty} \alpha_{n}\left(1-\alpha_{n}\right)>0$, and $\liminf _{n \rightarrow \infty}\left(1-\beta_{n}\right)>0$.

(iii) $f(x) \geq 0$ for all $x \in C$, and $f(0)=0$.

Then $\left\{x_{n}\right\}$ converges strongly to $p \in F$, where $p=\Pi_{F}^{f} x_{0}$.

If taking $\theta_{j} \equiv 0, A_{j} \equiv 0, \varphi_{j} \equiv 0, r_{j, n}=1$ and $\beta_{n} \equiv 0$, for all $n \in \mathbb{N}$ in algorithm (3.69) in Corollary 3.4, we obtain the following corollary.

Corollary 3.5. (Li et al. [42]) Let E be a uniformly convex and uniformly smooth Banach space, let $C$ be a nonempty closed and convex subset of $E$, let $S: C \rightarrow C$ be a weak relative nonexpansive mapping, and let $f: E \rightarrow \mathbb{R}$ be a convex lower semicontinuous mapping with $C \subset \operatorname{int}(D(f))$. Assume that $\left\{\alpha_{n}\right\}_{n=0}^{\infty}$ is sequence in $[0,1)$ such that $\limsup _{n \rightarrow \infty}\left(\alpha_{n}\right)<1$. Define a sequence $\left\{x_{n}\right\}$ in $C$ by the following algorithm:

$$
\begin{gathered}
x_{n}=x_{0} \in C, \quad C_{0}=C, \\
y_{n}=J^{-1}\left(\alpha_{n} J x_{n}+\left(1-\alpha_{n}\right) J S x_{n}\right), \\
C_{n+1}=\left\{w \in C_{n}: G\left(w, J y_{n}\right) \leq G\left(w, J x_{n}\right)\right\}, \\
x_{n+1}=\Pi_{C_{n+1}}^{f} x_{0}, \quad n \geq 1 .
\end{gathered}
$$

If $F(S)$ is nonempty, then $\left\{x_{n}\right\}$ converges to $\Pi_{F(S)}^{f} x_{0}$.

Taking $f(x)=0$ for all $x \in E$, we have $G(\xi, J x)=\phi(\xi, x)$ and $\Pi_{C}^{f} x=\Pi_{C} x$. By Theorem 3.1, then we obtain the following Corollaries.

Corollary 3.6. Let $C$ be a nonempty closed and convex subset of a uniformly smooth and strictly convex Banach space $E$ with the Kadec-Klee property. Let $\left\{S_{i}\right\}_{i=1}^{\infty}: C \rightarrow C$ be an infinite family of closed uniformly $L_{i}$-Lipschitz continuous and uniformly quasi- $\phi$-asymptotically nonexpansive mappings with a sequence $\left\{k_{n}\right\} \subset[1, \infty), k_{n} \rightarrow 1$. For each $j=1,2, \ldots, m$, let $\theta_{j}$ be a bifunction from $C \times C$ to $\mathbb{R}$ which satisfies conditions (A1)-(A4), let $A_{j}: C \rightarrow E^{*}$ be a continuous and monotone mapping, and let $\varphi_{j}: C \rightarrow \mathbb{R}$ be a lower semicontinuous and convex function. Assume 
that $F:=\left(\cap_{i=1}^{\infty} F\left(S_{i}\right)\right) \cap\left(\cap_{j=1}^{m} \operatorname{GMEP}\left(\theta_{j}, A_{j}, \varphi_{j}\right)\right) \neq \emptyset$. For an initial point $x_{0} \in E$ with $x_{1}=\Pi_{C_{1}} x_{0}$ and $C_{1}=C$, we define the sequence $\left\{x_{n}\right\}$ as follows:

$$
\begin{gathered}
z_{n}=J^{-1}\left(\alpha_{n, 0} J x_{n}+\sum_{i=1}^{\infty} \alpha_{n, i} J S_{i}^{n} x_{n}\right), \\
y_{n}=J^{-1}\left(\beta_{n} J x_{n}+\left(1-\beta_{n}\right) J z_{n}\right), \\
u_{n}=T_{r_{m, n}}^{Q_{m}} T_{r_{m-1, n}}^{Q_{m-1}} \cdots T_{r_{2, n}}^{Q_{2}} T_{r_{1, n}}^{Q_{1}} y_{n}, \\
C_{n+1}=\left\{z \in C_{n}: \phi\left(z, u_{n}\right) \leq \phi\left(z, x_{n}\right)+\left(k_{n}-1\right) M_{n}\right\}, \\
x_{n+1}=\prod_{C_{n+1}} x_{0}, \quad \forall n \geq 1,
\end{gathered}
$$

where $M_{n}=\sup _{q \in F} \phi\left(q, x_{n}\right),\left\{\alpha_{n, i}\right\}$ and $\left\{\beta_{n}\right\}$ are sequences in $[0,1]$ such that $\sum_{i=0}^{\infty} \alpha_{n, i}=1$ for all $n \geq 0$. If $\left\{x_{n}\right\}$ is satisfying the following conditions.

(i) $\left\{r_{j, n}\right\} \subset[d, \infty)$ for some $d>0$.

(ii) $\liminf _{n \rightarrow \infty} \alpha_{n, 0} \alpha_{n, i}>0$ for all $i \geq 1$ and $\liminf _{n \rightarrow \infty}\left(1-\beta_{n}\right)>0$.

Then $\left\{x_{n}\right\}$ converges strongly to $p \in F$, where $p=\Pi_{F} x_{0}$.

Corollary 3.7. Let $C$ be a nonempty closed and convex subset of a uniformly smooth and strictly convex Banach space $E$ with Kadec-Klee property. Let $S_{1}, S_{2}: C \rightarrow C$ be closed uniformly $L_{1}, L_{2}{ }^{-}$ Lipschitz continuous and uniformly quasi- $\phi$-asymptotically nonexpansive mappings with a sequence $\left\{k_{n}^{1}\right\} \subset[1, \infty), k_{n}^{1} \rightarrow 1$ and $\left\{k_{n}^{2}\right\} \subset[1, \infty), k_{n}^{2} \rightarrow 1$, respectively, such that $\left\{k_{n}\right\}=\sup \left\{\left\{k_{n}^{1}\right\},\left\{k_{n}^{2}\right\}\right\}$. For each $j=1,2, \ldots, m$ let $\theta_{j}$ be a bifunction from $C \times C$ to $\mathbb{R}$ which satisfies conditions (A1)-(A4), let $A_{j}: C \rightarrow E^{*}$ be a continuous and monotone mapping, and let $\varphi_{j}: C \rightarrow \mathbb{R}$ be a lower semicontinuous and convex function. Assume that $F:=\left(F\left(S_{1}\right) \cap F\left(S_{2}\right)\right) \cap\left(\cap_{j=1}^{m} \operatorname{GMEP}\left(\theta_{j}, A_{j}, \varphi_{j}\right)\right) \neq \emptyset$. For an initial point $x_{0} \in E$ with $x_{1}=\Pi_{C_{1}} x_{0}$ and $C_{1}=C$, we define the sequence $\left\{x_{n}\right\}$ as follows:

$$
\begin{gathered}
z_{n}=J^{-1}\left(\alpha_{n, 0} J x_{n}+\alpha_{n, 1} J S_{1}^{n} x_{n}+\alpha_{n, 2} J S_{2}^{n} x_{n}\right), \\
y_{n}=J^{-1}\left(\beta_{n} J x_{n}+\left(1-\beta_{n}\right) J z_{n}\right), \\
u_{n}=T_{r_{m, n}}^{Q_{m}} T_{r_{m-1, n}}^{Q_{m-1}} \cdots T_{r_{2, n}}^{Q_{2}} T_{r_{1, n}}^{Q_{1}} y_{n}, \\
C_{n+1}=\left\{z \in C_{n}: \phi\left(z, u_{n}\right) \leq \phi\left(z, x_{n}\right)+\left(k_{n}-1\right) M_{n}\right\}, \\
x_{n+1}=\prod_{C_{n+1}} x_{0}, \quad \forall n \geq 1,
\end{gathered}
$$

where $M_{n}=\sup _{q \in F} \phi\left(q, x_{n}\right),\left\{\alpha_{n, i}\right\}_{i=0}^{2}$ and $\left\{\beta_{n}\right\}$ are sequences in $[0,1]$ such that $\sum_{i=0}^{2} \alpha_{n, i}=1$ for all $n \geq 0$ with the following conditions.

(i) $\left\{r_{j, n}\right\} \subset[d, \infty)$ for some $d>0$.

(ii) $\liminf _{n \rightarrow \infty} \alpha_{n, 0} \alpha_{n, i}>0$ for all $i=1,2$ and $\liminf _{n \rightarrow \infty}\left(1-\beta_{n}\right)>0$.

Then $\left\{x_{n}\right\}$ converges strongly to $p \in F$, where $p=\Pi_{F} x_{0}$.

Remark 3.8. Corollary 3.6 and Corollary 3.7 extend and improve the results of many authors in the literature works. 


\section{Acknowledgments}

The authors would like to thank the referees for their careful reading and comments leading to the improvements of this paper. This research was supported by a grant from under the program Strategic Scholarships for Frontier Research Network for the Join Ph.D. Program Thai Doctoral degree from the Office of the Higher Education Commission, Thailand. Moreover, Mrs. Siwaporn Saewan was supported by King Mongkut's Diamond scholarship for Ph.D. program at King Mongkut's University of Technology Thonburi (KMUTT). Furthermore, the authors also would like to thank the National Research University Project of Thailand's Office of the Higher Education Commission (under the NRU-CSEC project no. 54000267) for their financial support during the preparation of this paper. Poom Kumam was supported by the Commission on Higher Education and the Thailand Research Fund under Grant no. MRG5380044.

\section{References}

[1] Y. I. Alber, "Metric and generalized projection operators in Banach spaces: properties and applications," in Theory and Applications of Nonlinear Operators of Accretive and Monotone Type, A. Kartsatos, Ed., vol. 178, pp. 15-50, Marcel Dekker, New York, NY, USA, 1996.

[2] J. Li, "The generalized projection operator on reflexive Banach spaces and its applications," Journal of Mathematical Analysis and Applications, vol. 306, no. 1, pp. 55-71, 2005.

[3] Y. I. Alber, "Generalized projection operators in Banach spaces: properties and applications," in Functional-Differential Equations, vol. 1 of Functional Differential Equations Israel Seminar, pp. 1-21, College of Judea and Samaria, Ariel, Israel, 1993.

[4] K.-Q. Wu and N.-J. Huang, "The generalised $f$-projection operator with an application," Bulletin of the Australian Mathematical Society, vol. 73, no. 2, pp. 307-317, 2006.

[5] J. Fan, X. Liu, and J. Li, "Iterative schemes for approximating solutions of generalized variational inequalities in Banach spaces," Nonlinear Analysis. Theory, Methods E Applications, vol. 70, no. 11, pp. 3997-4007, 2009.

[6] F. Kohsaka and W. Takahashi, "Block iterative methods for a finite family of relatively nonexpansive mappings in Banach spaces," Fixed Point Theory and Applications, vol. 2007, Article ID 21972, 18 pages, 2007.

[7] M. Kikkawa and W. Takahashi, "Approximating fixed points of nonexpansive mappings by the block iterative method in Banach spaces," International Journal of Computational and Numerical Analysis and Applications, vol. 5, no. 1, pp. 59-66, 2004.

[8] S. Plubtieng and K. Ungchittrakool, "Hybrid iterative methods for convex feasibility problems and fixed point problems of relatively nonexpansive mappings in Banach spaces," Fixed Point Theory and Applications, vol. 2008, Article ID 583082, 19 pages, 2008.

[9] S. Saewan and P. Kumam, "Modified hybrid block iterative algorithm for convex feasibility problems and generalized equilibrium problems for uniformly quasi- $\phi$-asymptotically nonexpansive mappings," Abstract and Applied Analysis, vol. 2010, Article ID 357120, 22 pages, 2010.

[10] S. Saewan and P. Kumam, "A new modified block iterative algorithm for uniformly quasi- $\phi$ asymptotically nonexpansive mappings and mixed equilibrium problems," accepted in Advances in Systems Science and Applications.

[11] E. Blum and W. Oettli, "From optimization and variational inequalities to equilibrium problems," The Mathematics Student, vol. 63, no. 1-4, pp. 123-145, 1994.

[12] P. Cholamjiak and S. Suantai, "Convergence analysis for a system of equilibrium problems and a countable family of relatively quasi-nonexpansive mappings in Banach spaces," Abstract and Applied Analysis, vol. 2010, Article ID 141376, 17 pages, 2010.

[13] P. L. Combettes and S. A. Hirstoaga, "Equilibrium programming in Hilbert spaces," Journal of Nonlinear and Convex Analysis, vol. 6, no. 1, pp. 117-136, 2005.

[14] C. Jaiboon and P. Kumam, "A general iterative method for solving equilibrium problems, variational inequality problems and fixed point problems of an infinite family of nonexpansive mappings," Journal of Applied Mathematics and Computing, vol. 34, no. 1-2, pp. 407-439, 2010. 
[15] P. Katchang and P. Kumam, "A new iterative algorithm of solution for equilibrium problems, variational inequalities and fixed point problems in a Hilbert space," Journal of Applied Mathematics and Computing, vol. 32, no. 1, pp. 19-38, 2010.

[16] P. Kumam, "A new hybrid iterative method for solution of equilibrium problems and fixed point problems for an inverse strongly monotone operator and a nonexpansive mapping," Journal of Applied Mathematics and Computing, vol. 29, no. 1-2, pp. 263-280, 2009.

[17] X. Qin, Y. J. Cho, and S. M. Kang, "Convergence theorems of common elements for equilibrium problems and fixed point problems in Banach spaces," Journal of Computational and Applied Mathematics, vol. 225, no. 1, pp. 20-30, 2009.

[18] X. Qin, S. Y. Cho, and S. M. Kang, "Strong convergence of shrinking projection methods for quasi- $\phi-$ nonexpansive mappings and equilibrium problems," Journal of Computational and Applied Mathematics, vol. 234, no. 3, pp. 750-760, 2010.

[19] S. Saewan, P. Kumam, and K. Wattanawitoon, "Convergence theorem based on a new hybrid projection method for finding a common solution of generalized equilibrium and variational inequality problems in Banach spaces," Abstract and Applied Analysis, vol. 2010, Article ID 734126, 25 pages, 2010.

[20] S. Saewan and P. Kumam, "A hybrid iterative scheme for a maximal monotone operator and two countable families of relatively quasi-nonexpansive mappings for generalized mixed equilibrium and variational inequality problems," Abstract and Applied Analysis, vol. 2010, Article ID 123027, 31 pages, 2010.

[21] K. Wattanawitoon and P. Kumam, "Generalized mixed equilibrium problems for maximal monotone operators and two relatively quasi-nonexpansive mappings," Thai Journal of Mathematics, vol. 9, no. 1, pp. 165-189, 2011.

[22] K. Wattanawitoon and P. Kumam, "Strong convergence to common fixed points for countable families of asymptotically nonexpansive mappings and semigroups," Fixed Point Theory and Applications, vol. 2010, Article ID 301868, 15 pages, 2010.

[23] N. Petrot, K. Wattanawitoon, and P. Kumam, "A hybrid projection method for generalized mixed equilibrium problems and fixed point problems in Banach spaces," Nonlinear Analysis. Hybrid Systems, vol. 4, no. 4, pp. 631-643, 2010.

[24] N. Petrot, K. Wattanawitoon, and P. Kumam, "Strong convergence theorems of modified Ishikawa iterations for countable hemi-relatively nonexpansive mappings in a Banach space," Fixed Point Theory and Applications, vol. 2009, Article ID 483497, 25 pages, 2009.

[25] S. Reich, "A weak convergence theorem for the alternating method with Bregman distances," in Theory and Applications of Nonlinear Operators of Accretive and Monotone Type, A. G. Kartsatos, Ed., vol. 178, pp. 313-318, Marcel Dekker, New York, NY, USA, 1996.

[26] W. Nilsrakoo and S. Saejung, "Strong convergence to common fixed points of countable relatively quasi-nonexpansive mappings," Fixed Point Theory and Applications, vol. 2008, Article ID 312454, 19 pages, 2008.

[27] Y. Su, D. Wang, and M. Shang, "Strong convergence of monotone hybrid algorithm for hemi-relatively nonexpansive mappings," Fixed Point Theory and Applications, vol. 2008, Article ID 284613, 8 pages, 2008.

[28] H. Zegeye and N. Shahzad, "Strong convergence theorems for monotone mappings and relatively weak nonexpansive mappings," Nonlinear Analysis. Theory, Methods E Applications, vol. 70, no. 7, pp. 2707-2716, 2009.

[29] R. P. Agarwal, Y. J. Cho, and X. Qin, "Generalized projection algorithms for nonlinear operators," Numerical Functional Analysis and Optimization, vol. 28, no. 11-12, pp. 1197-1215, 2007.

[30] D. Butnariu, S. Reich, and A. J. Zaslavski, "Asymptotic behavior of relatively nonexpansive operators in Banach spaces," Journal of Applied Analysis, vol. 7, no. 2, pp. 151-174, 2001.

[31] D. Butnariu, S. Reich, and A. J. Zaslavski, "Weak convergence of orbits of nonlinear operators in reflexive Banach spaces," Numerical Functional Analysis and Optimization, vol. 24, no. 5-6, pp. 489-508, 2003.

[32] Y. Censor and S. Reich, "Iterations of paracontractions and firmly nonexpansive operators with applications to feasibility and optimization," Optimization, vol. 37, no. 4, pp. 323-339, 1996.

[33] X. Qin, Y. J. Cho, S. M. Kang, and H. Zhou, "Convergence of a modified Halpern-type iteration algorithm for quasi- $\phi$-nonexpansive mappings," Applied Mathematics Letters, vol. 22, no. 7, pp. 10511055, 2009. 
[34] H. Zhou, G. Gao, and B. Tan, "Convergence theorems of a modified hybrid algorithm for a family of quasi- $\phi$-asymptotically nonexpansive mappings," Journal of Applied Mathematics and Computing, vol. 32, no. 2, pp. 453-464, 2010.

[35] Y. J. Cho, X. Qin, and S. M. Kang, "Strong convergence of the modified Halpern-type iterative algorithms in Banach spaces," Mathematical Journal of the Ovidius University of Constantza, vol. 17, no. 1, pp. 51-67, 2009.

[36] S.-Y. Matsushita and W. Takahashi, "A strong convergence theorem for relatively nonexpansive mappings in a Banach space," Journal of Approximation Theory, vol. 134, no. 2, pp. 257-266, 2005.

[37] Y. I. Alber and S. Reich, "An iterative method for solving a class of nonlinear operator equations in Banach spaces," Panamerican Mathematical Journal, vol. 4, no. 2, pp. 39-54, 1994.

[38] I. Cioranescu, Geometry of Banach Spaces, Duality Mappings and Nonlinear Problems, vol. 62, Kluwer Academic Publishers, Dordrecht, The Netherlands, 1990.

[39] S. Kamimura and W. Takahashi, "Strong convergence of a proximal-type algorithm in a Banach space," SIAM Journal on Optimization, vol. 13, no. 3, pp. 938-945, 2002.

[40] W. Takahashi, Nonlinear Functional Analysis, Yokohama Publishers, Yokohama, Japan, 2000.

[41] W. Takahashi and K. Zembayashi, "Strong convergence theorem by a new hybrid method for equilibrium problems and relatively nonexpansive mappings," Fixed Point Theory and Applications, vol. 2008, Article ID 528476, 11 pages, 2008.

[42] X. Li, N.-J. Huang, and D. O’Regan, "Strong convergence theorems for relatively nonexpansive mappings in Banach spaces with applications," Computers \& Mathematics with Applications, vol. 60, no. 5, pp. 1322-1331, 2010.

[43] Y. Shehu, "A new iterative scheme for countable families of weak relatively nonexpansive mappings and system of generalized mixed equilibrium problems," Abstract and Applied Analysis, vol. 2010, Article ID 861031, 24 pages, 2010.

[44] S. Chang, J. K. Kim, and X. R. Wang, "Modified block iterative algorithm for solving convex feasibility problems in Banach spaces," Journal of Inequalities and Applications, vol. 2010, Article ID 869684, p. 14, 2010.

[45] J. K. Kim, "Strong convergence theorems by hybrid projection methods for equilibriums problems and fixed point problems of the asymptotically quasi-phi-nonexpansive mappings," Fixed Point Theory and Application, vol. 2011, Article ID 901256, 20 pages, 2011.

[46] S. Saewan and P. Kumam, "The shrinking projection method for solving generalized equilibrium problem and common fixed points for asymptotically quasi- $\phi$-nonexpansive mappings," to appear in Fixed Point Theory and Applications.

[47] H. Hudzik, W. Kowalewski, and G. Lewicki, "Approximate compactness and full rotundity in Musielak-Orlicz spaces and Lorentz-Orlicz spaces," Zeitschrift für Analysis und ihre Anwendungen, vol. 25, no. 2, pp. 163-192, 2006.

[48] W. Takahashi and K. Zembayashi, "Strong and weak convergence theorems for equilibrium problems and relatively nonexpansive mappings in Banach spaces," Nonlinear Analysis. Theory, Methods $\mathcal{E}$ Applications, vol. 70, no. 1, pp. 45-57, 2009.

[49] S.-S. Zhang, "Generalized mixed equilibrium problem in Banach spaces," Applied Mathematics and Mechanics, vol. 30, no. 9, pp. 1105-1112, 2009.

[50] M. Liu, S.-S. Chang, and P. Zuo, “On a hybrid method for generalized mixed equilibrium problem and fixed point problem of a family of quasi- $\phi$-asymptotically nonexpansive mappings in Banach spaces," Fixed Point Theory and Applications, vol. 2010, Article ID 157278, 18 pages, 2010.

[51] K. Deimling, Nonlinear Functional Analysis, Springer, Berlin, Germany, 1985. 


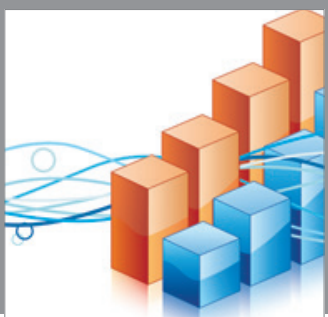

Advances in

Operations Research

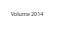

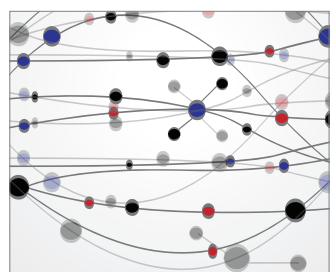

\section{The Scientific} World Journal
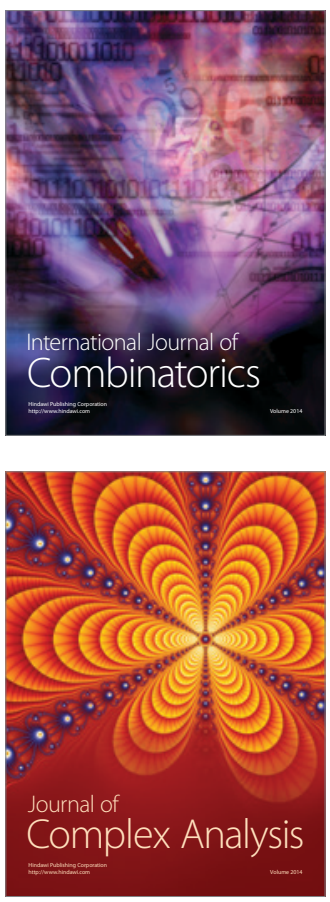

International Journal of

Mathematics and

Mathematical

Sciences
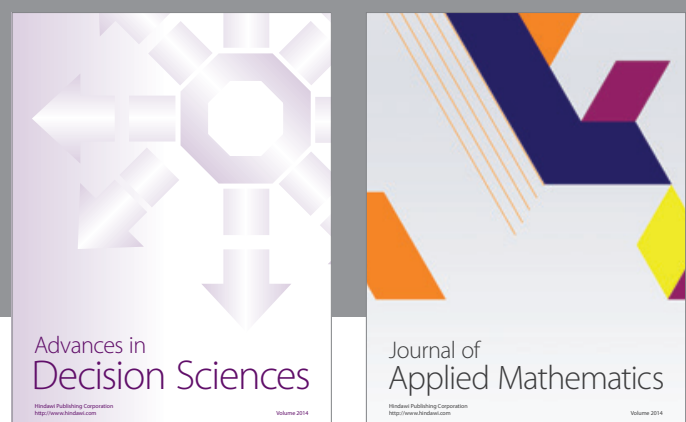

Journal of

Applied Mathematics
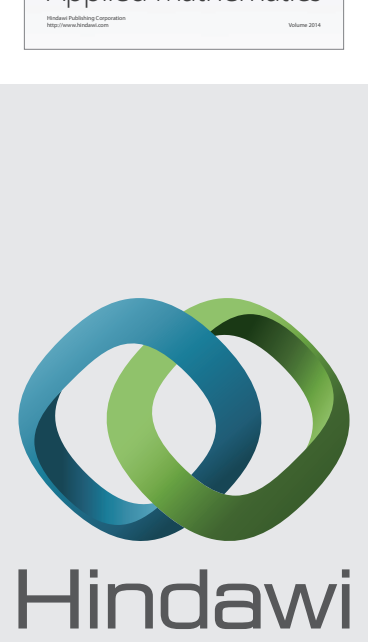

Submit your manuscripts at http://www.hindawi.com
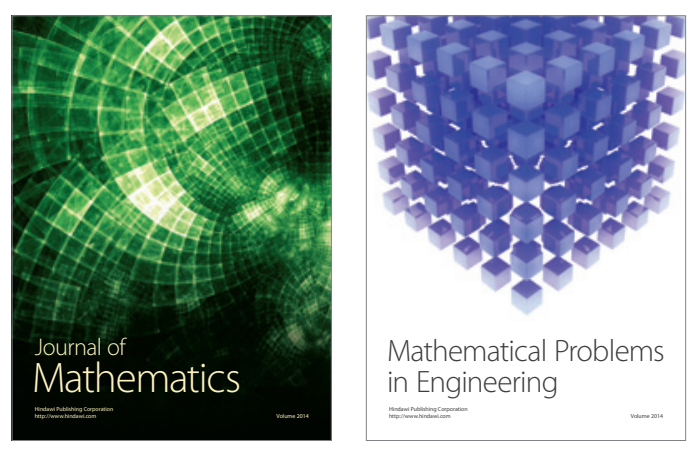

Mathematical Problems in Engineering
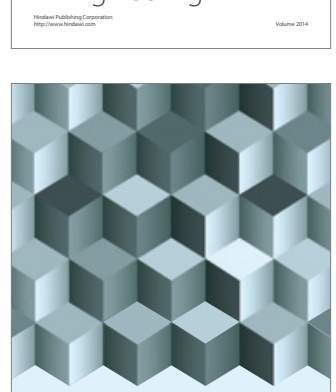

Journal of

Function Spaces
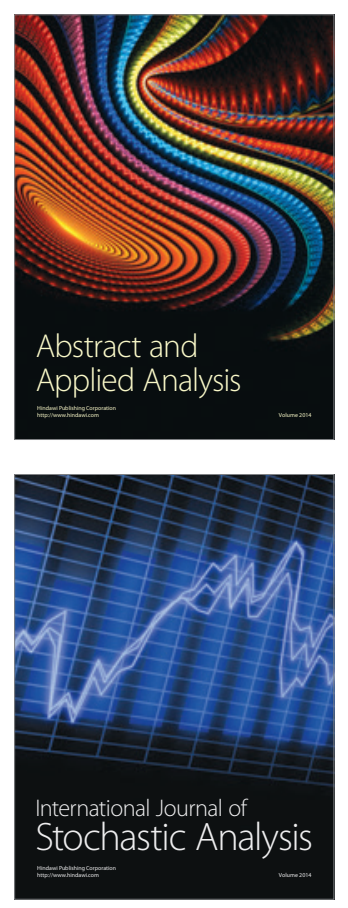

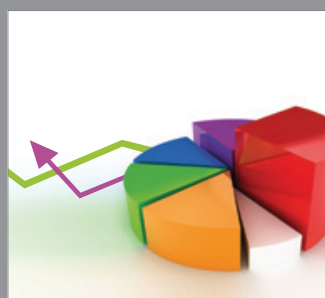

ournal of

Probability and Statistics

Promensencen
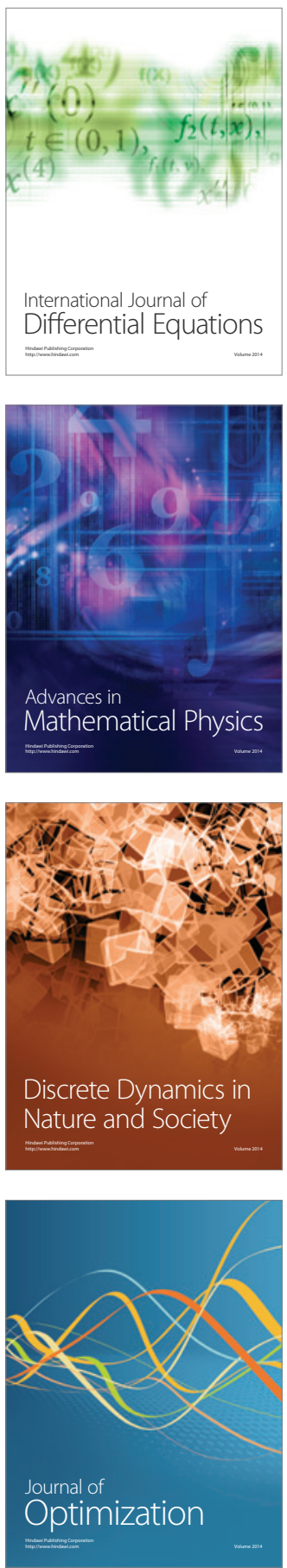